NISTIR 7763

\title{
Optimization of Particle Sizes in High Volume Fly Ash Blended Cements
}
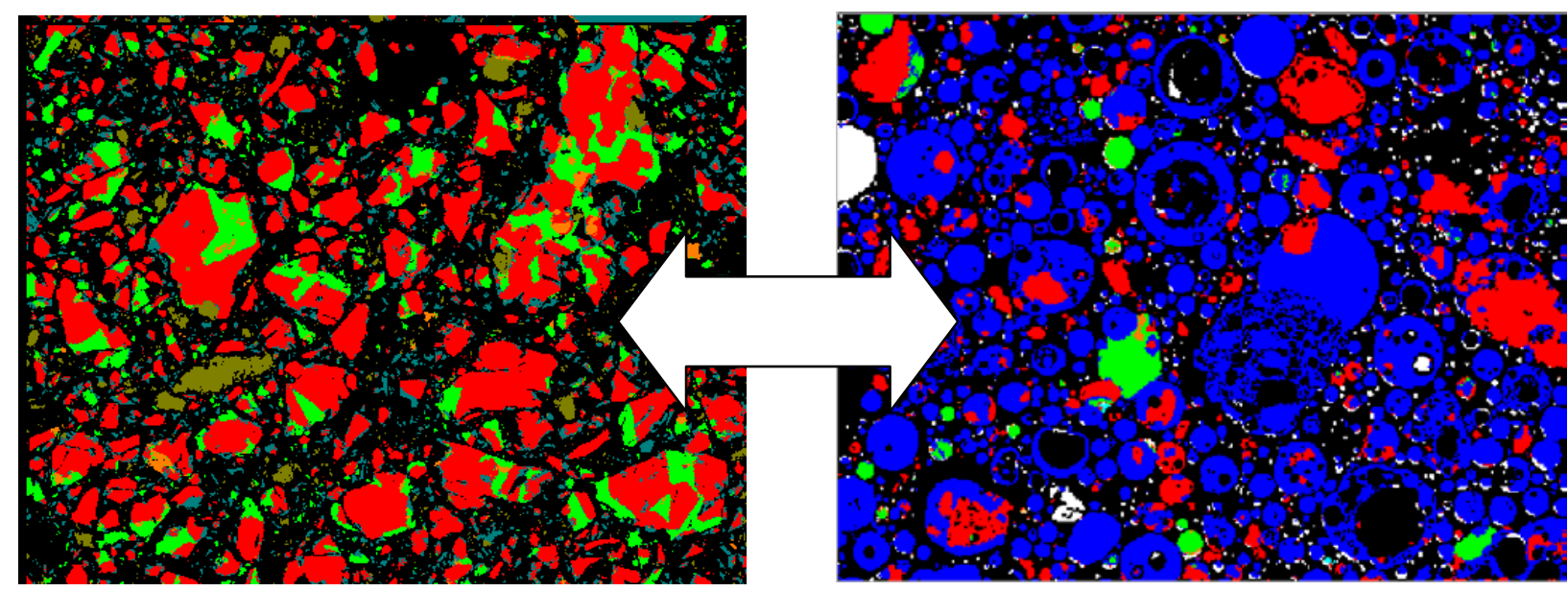

Dale P. Bentz

Chiara F. Ferraris James J. Filliben

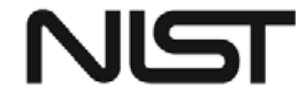

National Institute of Standards and Technology U.S. Department of Commerce 

NISTIR 7763

\title{
Optimization of Particle Sizes in High Volume Fly Ash Blended Cements
}

\author{
Dale P. Bentz \\ Chiara F. Ferraris \\ Materials and Construction Research Division \\ Engineering Laboratory \\ James J. Filliben \\ Statistical Engineering Division \\ Information Technology Laboratory
}

National Institute of Standards and Technology

Gaithersburg, MD 20899

Prepared for Roman Cement LLC

February 2011

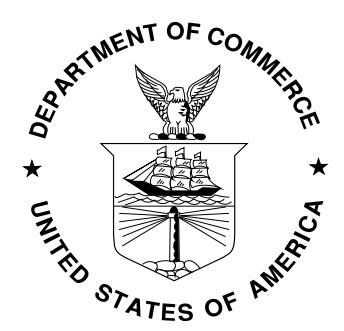

U.S. Department of Commerce Gary Locke, Secretary

National Institute of Standards and Technology Patrick D. Gallagher, Director 



\begin{abstract}
One major objective of the sustainable construction movement is to decrease the energy and carbon dioxide footprints of concrete. Since the production of portland cement is a major contributor in both of these areas, concretes with increasing quantities of supplementary cementitious materials replacing cement are drawing renewed interest. While cement is typically the majority component of the binder powder in a blended cement concrete, the physical and chemical properties of all of the powder components will strongly impact concrete performance. Following on a recent patent application filing by Roman Cement LLC on "High Early Strength Pozzolan Cement Blends" (patent granted in September 2010), the current study focuses on evaluating the properties of cement-fly ash blended cements, examining the influence of volumetric proportions of fly ash:cement and the individual particle size distributions (PSDs) of the cement and fly ash on a variety of performance properties including admixture requirements, setting times, heat release, strength, and autogenous deformation. Each of the three independent variables is examined at four different levels; a fractional factorial experimental design is employed to reduce the requisite number of mixtures from 64 to 16 . To provide for the fairest comparison, all mortars are prepared with constant volume fractions of components: water, sand, and binder powders (cement + fly ash). The basic objective of the study is to evaluate if these blended cements can match the performance of a $100 \%$ portland cement system, as exemplified by providing equivalent or superior strengths at both $1 \mathrm{~d}$ and $28 \mathrm{~d}$. The results indicate that by controlling the PSDs of the cement and fly ash, $20 \%$ fly ash replacements for cement on a volume basis can readily achieve this performance goal, while $35 \%$ replacements can approach this goal and even achieve it when the fly ash source (class) is carefully selected.
\end{abstract}




\section{Table of Contents}

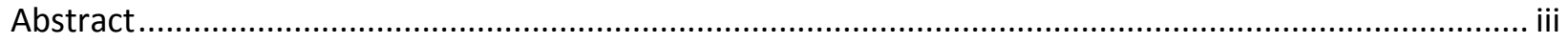

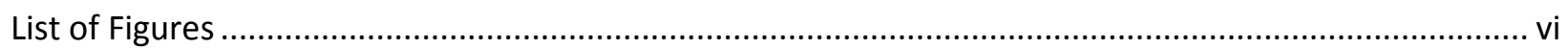

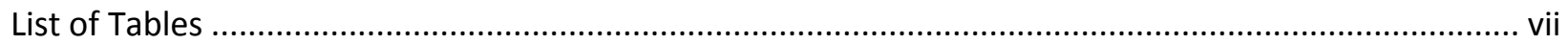

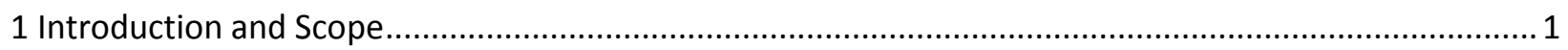

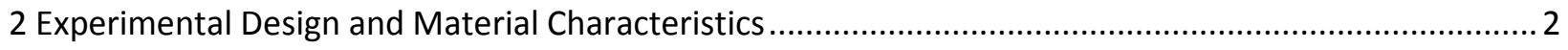

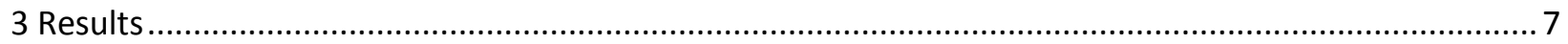

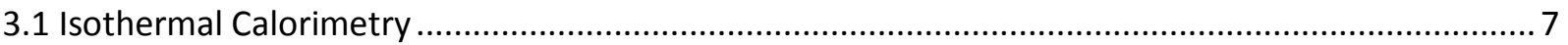

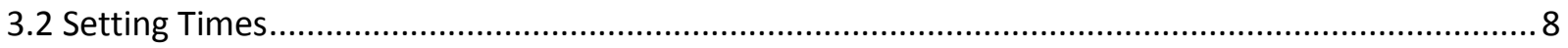

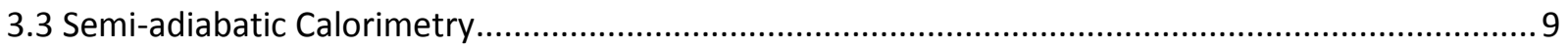

3.4 Compressive Strength Testing of Mortar Cubes ............................................................ 11

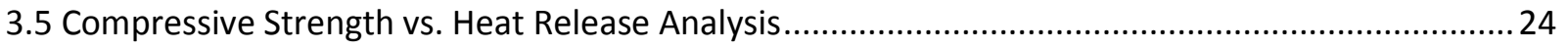

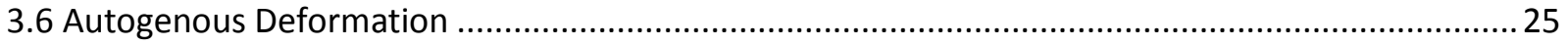

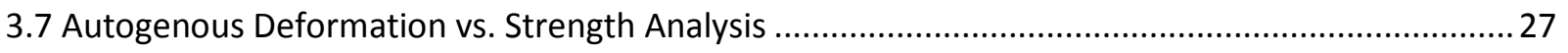

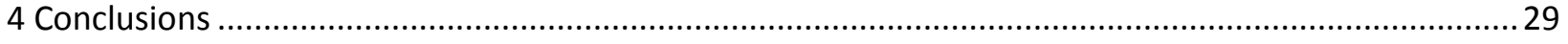

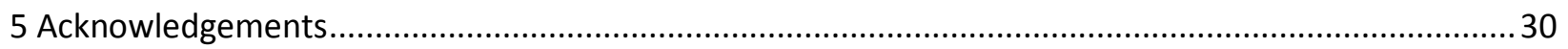

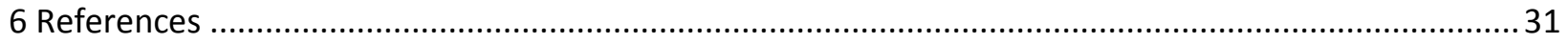

Appendix A - Procedures for Determining HRWRA Dosages ...................................................... 33

Appendix B - Measured Compressive Strength Values for all Mixtures .............................................36

Appendix C - Measured 28-d Net Autogenous Shrinkages for all Mixtures...........................................37 


\section{List of Figures}

Figure 1. Particle size distributions of the five cements shown as probability density functions. Each curve is the average of six individual measurements and the error bars (one standard deviation) would fall within the size of the shown symbols. ............................................................................................

Figure 2. Particle size distributions of the five Class F fly ashes shown as probability distribution functions. Each curve is the average of six individual measurements and the error bars (one standard deviation) would fall within the size of the shown symbols................................................................ 4 Figure 3. Isothermal calorimetry results for mortar mixtures \#9 (left) and \#18 (right) indicating excellent repeatability between the two replicates in each case....................................................................... 7

Figure 4. Cumulative heat release curves for the first $24 \mathrm{~h}$ of curing for the 20 mortar mixtures.............. 8

Figure 5. Semi-adiabatic temperature curves for the first $48 \mathrm{~h}$ of curing for the 20 mortar mixtures........ 10 Figure 6. Regression analysis for maximum temperature vs. cement surface area (X variable 1), fly ash surface area (X variable 2), and fly ash volume fraction in percent (X variable 3) ................................11 Figure 7. One-day and 3-d mean compressive strengths for the 20 mortar mixtures investigated in the current study. Standard deviations are provided in Appendix B....................................................... 12 Figure 8. Seven-day and 28-d mean compressive strengths for the 20 mortar mixtures investigated in the current study. Standard deviations are provided in Appendix B....................................................... 12 Figure 9. 91-d and 182-d mean compressive strengths for the 20 mortar mixtures investigated in the current study. Standard deviations are provided in Appendix B....................................................... 13 Figure 10. Mean compressive strength at $1 \mathrm{~d}$ vs. the three factors of cement PSD, fly ash PSD, and fly ash volumetric proportion.

Figure 11. Regression analysis for strength at $1 \mathrm{~d}$ vs. cement surface area and fly ash volume fraction in

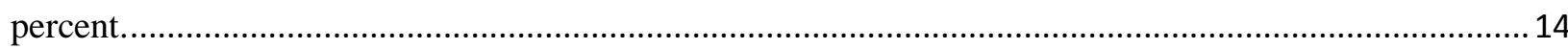

Figure 12. Regression analysis for strength at $1 \mathrm{~d}$ according to equation 1 ........................................... 15 Figure 13. Mean compressive strength at $3 \mathrm{~d}$ vs. the three factors of cement PSD, fly ash PSD, and fly ash volumetric proportion.

Figure 14. Regression analysis for strength at $3 \mathrm{~d}$ vs. cement surface area and fly ash volume fraction in

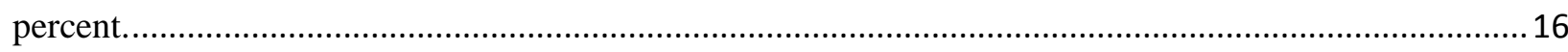

Figure 15. Regression analysis for strength at $3 \mathrm{~d}$ according to equation (1)........................................ 16 Figure 16 . Mean compressive strength at $7 \mathrm{~d}$ vs. the three factors of cement PSD, fly ash PSD, and fly ash volumetric proportion.

Figure 17. Regression analysis for strength at $7 \mathrm{~d}$ vs. cement surface area and fly ash volume fraction in

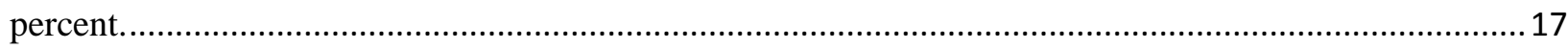

Figure 18. Regression analysis for strength at $7 \mathrm{~d}$ according to equation (1)....................................... 18 Figure 19. Mean compressive strength at $28 \mathrm{~d}$ vs. the three factors of cement PSD, fly ash PSD, and fly

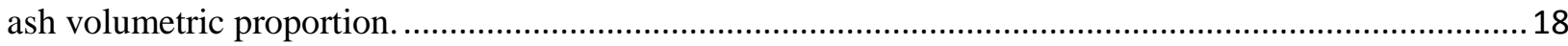
Figure 20. Regression analysis for strength at $28 \mathrm{~d}$ vs. cement surface area, fly ash volume fraction in percent, and fly ash surface area. ............................................................................................. 19

Figure 21. Regression analysis for strength at $28 \mathrm{~d}$ according to equation (1)...................................... 19 
Figure 22. Mean compressive strength at $91 \mathrm{~d}$ vs. the three factors of cement PSD, fly ash PSD, and fly ash volumetric proportion.

Figure 23. Regression analysis for strength at $91 \mathrm{~d}$ vs. fly ash volume fraction in percent and fly ash surface area. 20

Figure 24. Regression analysis for strength at $91 \mathrm{~d}$ according to equation (1).

Figure 25. Mean compressive strength at $182 \mathrm{~d}$ vs. the three factors of cement PSD, fly ash PSD, and fly ash volumetric proportion.

Figure 26. Regression analysis for strength at $182 \mathrm{~d}$ vs. cement surface area, fly ash volume fraction in

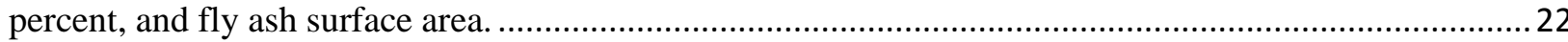

Figure 27. Regression analysis for strength at $182 \mathrm{~d}$ according to equation (1) ....................................22 Figure 28. Plot of mean mortar cube compressive strengths vs. heat release for ages of $1 \mathrm{~d}, 3 \mathrm{~d}$, and $7 \mathrm{~d}$, indicating a generally linear relationship.

Figure 29. Regression analysis for fit of $1 \mathrm{~d}, 3 \mathrm{~d}$, and $7 \mathrm{~d}$ compressive strength vs. cumulative heat release measured at the same ages.

Figure 30. Autogenous deformation measured during the course of $56 \mathrm{~d}$ for mortar mixture \#17, providing an indication of typical measurement variability.

Figure 31. Mean net autogenous shrinkage (deformation) at $28 \mathrm{~d}$ vs. the three factors of cement PSD, fly ash PSD, and fly ash/cement ratio.

Figure 32. Regression analysis for net autogenous shrinkage at $28 \mathrm{~d}$ vs. cement surface area, fly ash volume fraction in percent, and fly ash surface area.... 27

Figure 33. 28-d net autogenous shrinkage vs. 28-d compressive strength. 28

Figure 34: Bingham model and calculation of the plastic viscosity and yield stress. 33

\section{List of Tables}

Table 1. Experimental design employed in the present study.............................................................. 3

Table 2. PSD-estimated surface areas for the powder materials............................................................ 5

Table 3. Measured fresh properties of mortar mixtures. ......................................................................... 6

Table 4. Setting times (ASTM C191) of pastes from a subset of the mortar mixtures............................. 9

Table 5. Linear regression coefficients vs. age for compressive strength data for primary independent

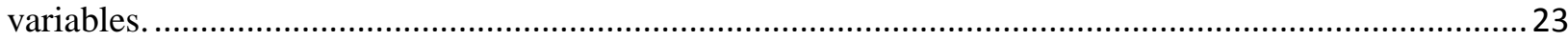

Table 6. Linear regression coefficients vs. age for compressive strength data according to equation (1).. 23

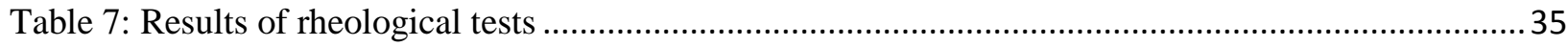

Table 8. Measured mortar cube compressive strengths (means and standard deviations) for the 20 mortar

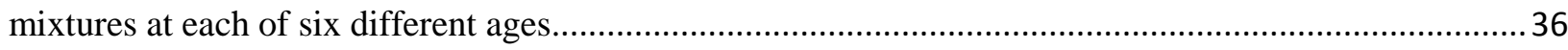

Table 9. Measured 28-d net autogenous shrinkages for the 20 mortar mixtures. .................................... 37 


\section{Introduction and Scope}

It is well established that the particle size distribution (PSD) of the cement plays a major role in influencing the fresh and hardened properties of cement-based materials, particularly at early ages [1-4]. In fact, one of the major trends in concrete technology in the past fifty years has been a consistent increase in the fineness of cement [5], mainly to provide increased earlyage strengths to support fast track construction. While these cements are typically optimized for utilization in ordinary portland cement concretes, another more recent trend, partially in response to an increased focus on sustainability, is an increase in the utilization of supplementary cementitious materials (SCMs) such as slag, fly ash, and silica fume in concretes. Cements that are optimized for a $100 \%$ cement binder may not be optimized for utilization in a blended product. With this in mind, Roman Cement LLC has recently filed a patent for "High Early Strength Pozzolan Cement Blends," where the PSDs of both the cement and pozzolan are controlled to produce “optimum” (early age) properties [6]. For example, delayed setting times and low early age strengths are two of the most common problems associated with the production of high volume fly ash (HVFA) concretes [7]. With this in mind, the purpose of the ongoing Cooperative Research and Development Agreement (CRADA) between Roman Cement LLC and the National Institute of Standards and Technology (NIST) is to conduct a statisticallydesigned experiment to determine the influence of cement and fly ash particle characteristics on a variety of performance variables including high range water-reducing admixture requirements, heat release, semi-adiabatic temperature rise, setting times, strength development at both early and later ages, and autogenous deformation. The basic premise is that blending a finer cement with a coarser fly ash may produce a superior product, in terms of increasing early age strengths while maintaining later age performance. The present report summarizes and interprets the experimental results obtained in this study. 


\section{Experimental Design and Material Characteristics}

A commercially available Type I/II (ASTM C150 [8]) cement and a Class F fly ash (ASTM C618 [9]) were obtained by Roman Cement LLC from their respective manufacturers. According to its manufacturer, the cement has a Blaine fineness of $376 \mathrm{~m}^{2} / \mathrm{kg}$ and a potential Bogue phase composition of $57 \% \mathrm{C}_{3} \mathrm{~S}, 15 \% \mathrm{C}_{2} \mathrm{~S}, 7 \% \mathrm{C}_{3} \mathrm{~A}$, and $10 \% \mathrm{C}_{4} \mathrm{AF}$ by mass. Its measured density is $3200 \mathrm{~kg} / \mathrm{m}^{3} \pm 10 \mathrm{~kg} / \mathrm{m}^{3}$ (ASTM C188 [8]). According to its manufacturer, the Class F fly ash contains major oxides of $52.9 \% \mathrm{SiO}_{2}, 26.4 \% \mathrm{Al}_{2} \mathrm{O}_{3}, 8.5 \% \mathrm{Fe}_{2} \mathrm{O}_{3}$, and $2.1 \%$ $\mathrm{CaO}$ by mass, with measured strength activity indices (ASTM C311/ASTM C618 [9]) of $88 \%$ and $92 \%$ at $7 \mathrm{~d}$ and $28 \mathrm{~d}$, respectively. Its density is reported as $2300 \mathrm{~kg} / \mathrm{m}^{3}$ by the manufacturer. For one mixture, a Type III cement [4,8] with a density of $3250 \mathrm{~kg} / \mathrm{m}^{3}$ and a Blaine fineness of $613 \mathrm{~m}^{2} / \mathrm{kg}$ was employed.

Three variables were selected as candidates for influencing the optimization of properties of cement/fly ash blends: cement PSD, fly ash PSD, and fly ash volumetric proportion percentage. Since the goal of this project was to evaluate the performance of "fine" cements blended with "coarse" fly ashes, the cement PSDs were characterized by their $\mathrm{D}_{90}{ }^{1}$ value while those of the fly ashes were characterized by their $\mathrm{D}_{10}$ value instead. Via grinding and classification, four cements with target $\mathrm{D}_{90}$ values of $7.5 \mu \mathrm{m}, 10 \mu \mathrm{m}, 15 \mu \mathrm{m}$, and $20 \mu \mathrm{m}$ were obtained by Roman Cement and supplied to NIST, while four fly ashes with target $\mathrm{D}_{10}$ values of $5 \mu \mathrm{m}, 10 \mu \mathrm{m}, 15 \mu \mathrm{m}$, and $20 \mu \mathrm{m}$ were also produced. The actual measured $\mathrm{D}_{90}$ values for the four cements were nominally $9 \mu \mathrm{m}$ (cement 10), $11 \mu \mathrm{m}$ (cement 9), $12 \mu \mathrm{m}$ (cement 8), and 24 $\mu \mathrm{m}$ (cement 7), in contrast to the $\mathrm{D}_{90}$ of $36 \mu \mathrm{m}$ for the original cement (cement 6). The actual measured fly ash $\mathrm{D}_{10}$ values were nominally $4 \mu \mathrm{m}$ (fly ash 5), $11 \mu \mathrm{m}$ (fly ash 4 ), $13 \mu \mathrm{m}$ (fly ash 3), and $15 \mu \mathrm{m}$ (fly ash 2) in contrast to $2.7 \mu \mathrm{m}$ as measured for the original fly ash (fly ash 1 ). Finally, the four levels for the fly ash volume percentage were set at $20 \%, 35 \%, 50 \%$, and $65 \%$. Since three variables with four levels implies 64 runs for a complete factorial experiment, the number of experimental runs was reduced to 16 by applying design of experiment principles to create a fractional factorial experimental design [10]. The selected experimental design with both encoded-level $(0,1,2$, and 3$)$ variables and original values is provided in Table 1 . In addition to these sixteen mortar mixtures, four additional mixtures were investigated: 1 ) a control mixture produced with the original cement (two replicates prepared), 2) a 50:50 volumetric blend of the original cement and original fly ash as a reference point for the performance of an existing HVFA blend, 3) a mixture containing $35 \%$ of an unprocessed (no grinding or subsequent classification) Class C fly ash with $65 \%$ of the cement 9 with a $\mathrm{D}_{90}$ of $11 \mu \mathrm{m}$, to investigate the influence of fly ash class on early and later age performance, and 4) a mixture with a Type III cement and $35 \%$ of the $4 \mu \mathrm{m}$ Class $\mathrm{F}$ fly ash to provide a reference point to the current industry practice of sometimes employing a Type III cement in concrete during winter construction. The control and 50:50 reference mixtures were the first two to be prepared. Following this, the run order of the next 16 mixtures was randomized as shown in Table 1. After these sixteen mixtures were prepared, a replicate of the control mixture was executed. Next, the mixture with $35 \%$ of a

\footnotetext{
${ }^{1} \mathrm{D}_{90}$ indicates that $90 \%$ of the particles on a mass basis are below a given size (diameter) while $\mathrm{D}_{10}$ indicates that $10 \%$ of the particles on a mass basis are below a given diameter.
} 
Class C fly ash was prepared and evaluated. Finally, the mixture with the Type III cement was prepared.

Table 1. Experimental design employed in the present study.

\begin{tabular}{|c|c|c|c|c|c|c|c|}
\hline \multirow{3}{*}{$\begin{array}{c}\text { Mixture } \\
\text { order } \\
(3-18)\end{array}$} & \multirow{2}{*}{\multicolumn{3}{|c|}{ Encoded Variable Levels }} & \multicolumn{3}{|c|}{ Original (targeted) variables } & \multirow{3}{*}{$\begin{array}{c}\text { HRWRA } \\
\text { dosage } \\
\text { (g HRWRA/ } \\
100 \text { g binder) }\end{array}$} \\
\hline & & & & \multirow{2}{*}{$\begin{array}{c}\mathrm{D}_{90} \\
\text { Cement } \\
(\mu \mathrm{m}) \\
{[\mathrm{ID} \#]}\end{array}$} & \multirow{2}{*}{$\begin{array}{c}\mathrm{D}_{10} \\
\text { Fly ash } \\
(\mu \mathrm{m}) \\
{[\mathrm{ID} \#]}\end{array}$} & \multirow{2}{*}{$\begin{array}{l}\text { Volumetric } \\
\text { fly ash } \\
\text { content (\%) }\end{array}$} & \\
\hline & $\begin{array}{c}\mathrm{A}=\text { cement } \\
\text { PSD }\end{array}$ & $\begin{array}{c}\text { B=fly } \\
\text { ash } \\
\text { PSD }\end{array}$ & $\begin{array}{c}C=F A \\
\text { content }= \\
(A+B) \bmod 4\end{array}$ & & & & \\
\hline 9 & 0 & 0 & 0 & $7.5[10]$ & $5[5]$ & 20 & 1.00 \\
\hline 10 & 0 & 1 & 1 & $7.5[10]$ & $10[4]$ & 35 & 0.67 \\
\hline 12 & 0 & 2 & 2 & $7.5[10]$ & $15[3]$ & 50 & 0.05 \\
\hline 7 & 0 & 3 & 3 & $7.5[10]$ & $20[2]$ & 65 & 0.00 \\
\hline 8 & 1 & 0 & 1 & 10 [9] & $5[5]$ & 35 & 0.48 \\
\hline 6 & 1 & 1 & 2 & $10[9]$ & $10[4]$ & 50 & 0.28 \\
\hline 18 & 1 & 2 & 3 & $10[9]$ & $15[3]$ & 65 & 0.00 \\
\hline 17 & 1 & 3 & 0 & $10[9]$ & $20[2]$ & 20 & 1.00 \\
\hline 16 & 2 & 0 & 2 & 15 [8] & $5[5]$ & 50 & 0.05 \\
\hline 11 & 2 & 1 & 3 & 15 [8] & $10[4]$ & 65 & 0.00 \\
\hline 14 & 2 & 2 & 0 & $15[8]$ & 15 [3] & 20 & 0.80 \\
\hline 5 & 2 & 3 & 1 & $15[8]$ & $20[2]$ & 35 & 0.37 \\
\hline 15 & 3 & 0 & 3 & 20 [7] & $5[5]$ & 65 & 0.00 \\
\hline 13 & 3 & 1 & 0 & 20 [7] & $10[4]$ & 20 & 0.05 \\
\hline 3 & 3 & 2 & 1 & 20 [7] & 15 [3] & 35 & 0.00 \\
\hline 4 & 3 & 3 & 2 & 20 [7] & $20[2]$ & 50 & 0.00 \\
\hline
\end{tabular}

The particle size distributions (PSDs) of the original and processed cements and fly ashes were measured using a laser diffraction technique and are provided in Figures 1 and 2. Based on these measured PSDs and assuming spherical particles, the cement and fly ash surface areas (Table 2) were calculated for each mortar mixture examined in the present study, and considered to be a more quantitative variable than the targeted $\mathrm{D}_{90}$ or $\mathrm{D}_{10}$ values for representing the two powder components of the mixtures in subsequent regression analysis. In Table 2, it can be observed that the PSD-estimated surface area for cement $6,485 \mathrm{~m}^{2} / \mathrm{kg}$, is significantly higher than its Blaine value of $376 \mathrm{~m}^{2} / \mathrm{kg}$.

Because the mortars were prepared with constant mixture volume fractions of water (0.24), sand (0.55), and binder (cement + fly ash, 0.21$)^{2}$, the addition of a high range water reducing admixture (HRWRA) was necessary in some of the mixtures to maintain adequate flow and workability for specimen preparation. A polycarboxylate-type HRWRA known to produce minimal retardation was selected for this purpose. Screening studies were first conducted by

\footnotetext{
${ }^{2}$ The water-to-cement ratio by mass ( $w / c$ ) of the control mortar was 0.35 . For the $20 \%, 35 \%$, $50 \%$, and $65 \%$ mixtures, the corresponding water-to-cementitious materials ratios $(\mathrm{w} / \mathrm{cm})$ on a mass basis were 0.365, 0.386, 0.406, and 0.427, respectively.
} 


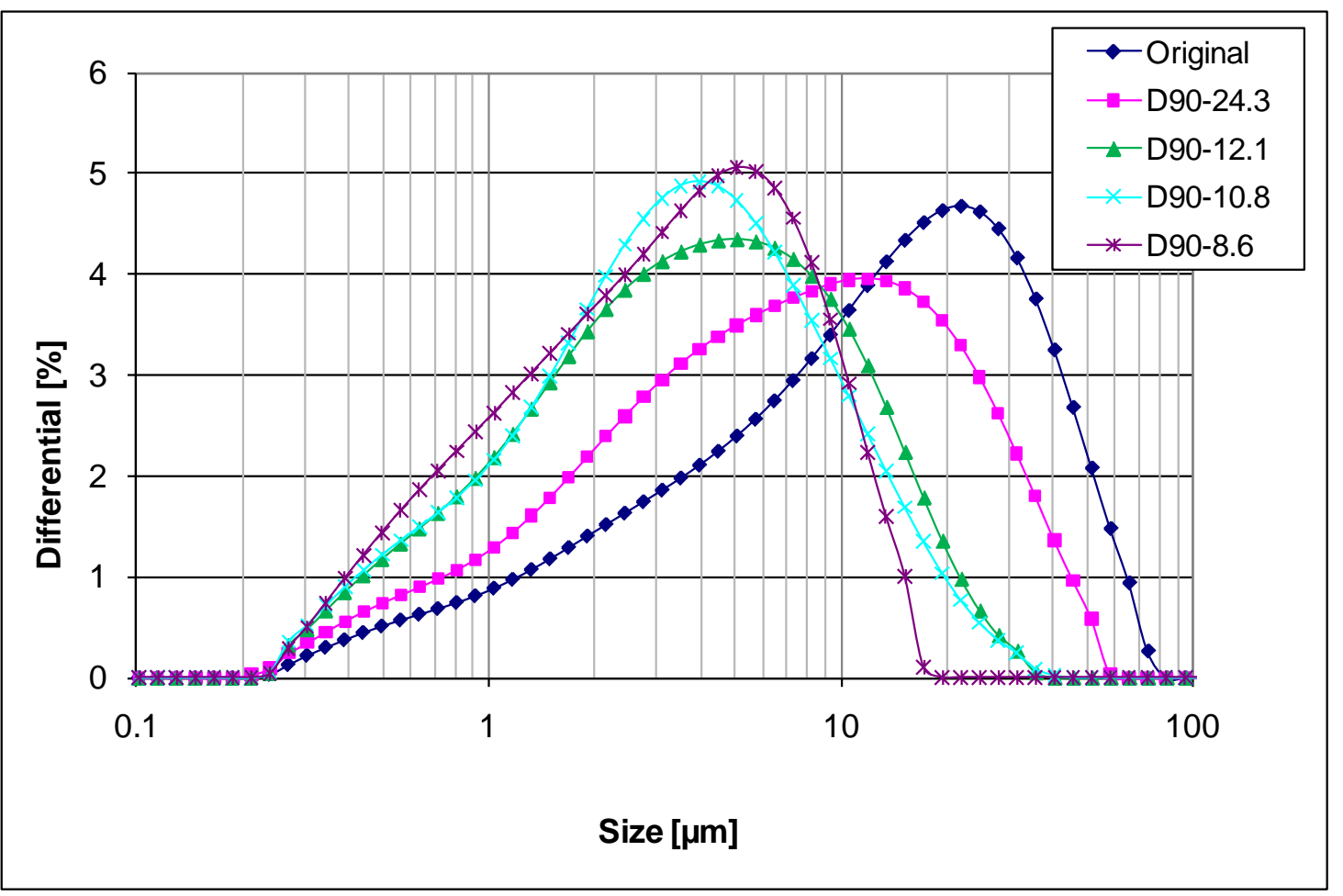

Figure 1. Particle size distributions of the five cements shown as probability density functions. Each curve is the average of six individual measurements and the error bars (one standard deviation) would fall within the size of the shown symbols.

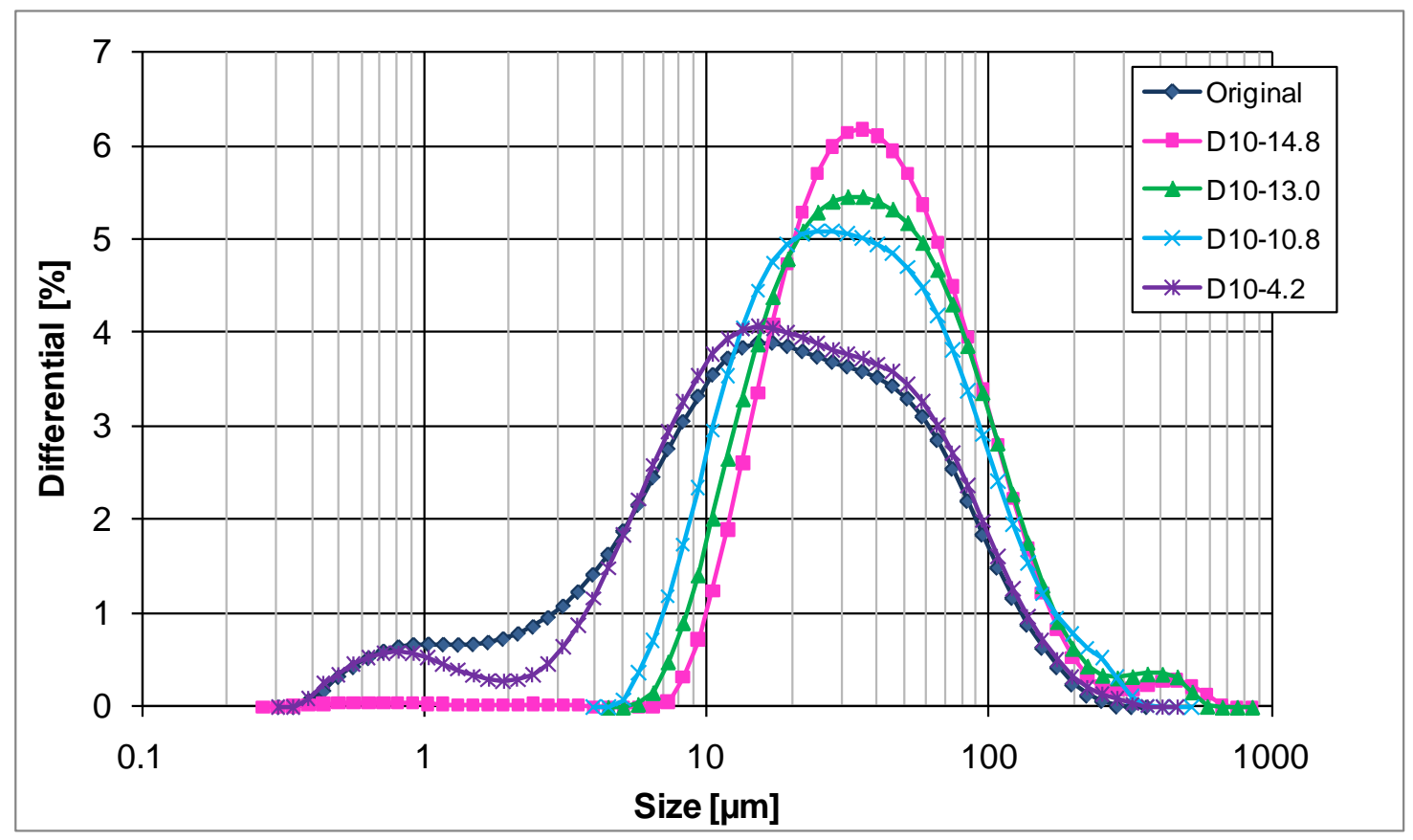

Figure 2. Particle size distributions of the five Class F fly ashes shown as probability distribution functions. Each curve is the average of six individual measurements and the error bars (one standard deviation) would fall within the size of the shown symbols. 
Table 2. PSD-estimated surface areas for the powder materials.

\begin{tabular}{|c|c|}
\hline Cement or Fly Ash ID & PSD-estimated surface area $\left(\mathrm{m}^{2} / \mathrm{kg}\right)$ \\
\hline Fly ash 1 & 432 \\
\hline Fly ash 2 & 103 \\
\hline Fly ash 3 & 96 \\
\hline Fly ash 4 & 114 \\
\hline Fly ash 5 & 379 \\
\hline Cement 6 & 485 \\
\hline Cement 7 & 670 \\
\hline Cement 8 & 964 \\
\hline Cement 9 & 1017 \\
\hline Cement 10 & 1096 \\
\hline
\end{tabular}

performing rheological measurements in blended cement pastes with various addition levels of the HRWRA as described in detail in Appendix A. The final HRWRA dosages employed in each mortar are included in Table 1. Regardless of the measured flow values, all mortar mixtures exhibited sufficient workability to mold mortar cubes for compressive strength testing and corrugated tubes for measurement of autogenous deformation (ASTM C1698 [9]). No HRWRA addition was required for either the control mixture (\#1) or the reference 50:50 mixture (\#2). For mortar mixture \#19 prepared with $35 \%$ of the Class C fly ash, a HRWRA dosage of $0.67 \mathrm{~g}$ of HRWRA per $100 \mathrm{~g}$ binder was employed, while a dosage of $0.48 \mathrm{~g}$ HRWRA per $100 \mathrm{~g}$ binder was required for mortar mixture \#20 prepared with the Type III cement. As expected, mixtures with a higher cement content (lower fly ash proportion) or employing a finer cement required a higher dosage of the HRWRA to provide sufficient flow. For these dosages, the flows measured on the mortar mixtures (ASTM C1437 [8]) are summarized in Table 3.

Each fresh mortar mixture was evaluated for air content via unit weight (cup) measurements according to ASTM C185 [8] and temperature (see Table 3), in addition to flow. Then, appropriate specimens were prepared for the following measurements:

1) Isothermal calorimetry - the heat of hydration was measured during the course of $7 \mathrm{~d}$ on premixed (as opposed to being mixed in situ in the calorimeter cells) sealed mortar samples with a mass of about $8 \mathrm{~g}$ using a TAM Air Calorimeter ${ }^{3}$; to provide an indication of variability, two specimens from the same batch were evaluated in neighboring calorimeter cells for each experiment,

2) Semi-adiabatic calorimetry - the semi-adiabatic temperature was measured during the course of $3 \mathrm{~d}$ on a single sealed mortar specimen with a mass of approximately $330 \mathrm{~g}$ using a custombuilt semi-adiabatic calorimeter unit [11]; replicate specimens from separate batches have indicated a standard deviation of $1.4^{\circ} \mathrm{C}$ in the maximum specimen temperature achieved during a 3 d test,

3) Compressive strength - measured at $1 \mathrm{~d}, 3 \mathrm{~d}, 7 \mathrm{~d}, 28 \mathrm{~d}, 91 \mathrm{~d}$, and $182 \mathrm{~d}$ on mortar cube specimens cured in a saturated calcium hydroxide solution, according to the procedures in ASTM C 109 [8], but with a loading rate of $20.7 \mathrm{MPa} / \mathrm{min}$, switching to deformation control (at

${ }^{3}$ Certain commercial products are identified in this report to specify the materials used and procedures employed. In no case does such identification imply endorsement by the National Institute of Standards and Technology, nor does it indicate that the products are necessarily the best available for the purpose. 
Table 3. Measured fresh properties of mortar mixtures.

\begin{tabular}{|c|c|c|c|}
\hline Mortar mixture & Flow table value (\%) & Air content (\%) & Temperature $\left({ }^{\circ} \mathrm{C}\right)$ \\
\hline 1 (Control) & $114,92.7$ & $2.25,2.32$ & 23,23 \\
\hline 2 & 135 & 1.41 & 22 \\
\hline 3 & 105 & 2.49 & 21 \\
\hline 4 & 104 & 3.40 & 22 \\
\hline 5 & 98 & 4.00 & 21 \\
\hline 6 & 103 & 3.56 & 21 \\
\hline 7 & 84.7 & 2.68 & 21 \\
\hline 8 & 103 & 3.47 & 23 \\
\hline 9 & 98 & 4.11 & 25 \\
\hline 10 & 109 & 3.53 & 25 \\
\hline 11 & 107 & 2.17 & 23 \\
\hline 12 & 84.7 & 3.05 & 24 \\
\hline 13 & 92 & 3.23 & 23 \\
\hline 14 & 135 & 3.87 & 25 \\
\hline 15 & 134 & 1.93 & 23 \\
\hline 16 & 85.3 & 2.20 & 24 \\
\hline 17 & 131 & 4.63 & 24 \\
\hline 18 & 93.3 & 2.25 & 23 \\
\hline 19 (C ash) & 125 & 4.38 & 25 \\
\hline 20 (Type III cement) & Not measured & 3.74 & 25 \\
\hline
\end{tabular}

the instantaneous deformation rate) once a stress of $13.8 \mathrm{MPa}$ was reached; three specimens prepared from a single batch were evaluated at each time, with the averages and standard deviations provided in the results to follow (see Appendix A), and

4) Autogenous deformation - measured on triplicate or duplicate sealed mortar specimens prepared from a single batch, sealed in corrugated tubes according to the procedures in ASTM C1698 [9]; in the ASTM C1698 standard, the single laboratory precision is listed as 30 microstrain for mortar specimens.

A subset of the mixtures (\#1, \#2, \#8, \#9, and \#14) were evaluated with respect to setting time by performing ASTM C191 [8] measurements on cement pastes prepared in a high shear blender, but with the following modification to better prevent any evaporation from the specimen during the course of the test [12]. A moist sponge was held in place in the bottom of a foam cup using toothpicks, and the inverted cup placed on top of the truncated conical cement paste specimen, in an effort to maintain a near $100 \%$ relative humidity environment surrounding the hardening cement paste. The cup was removed prior to each measurement and returned immediately after recording the needle penetration. In addition to this, the mass of the specimen and its holder (conical mold and bottom plate) was determined at the beginning of the test and immediately after final set was achieved. Typical mass loss is less than $0.5 \%$ (specimen basis) even for specimens with final setting times of $8 \mathrm{~h}$ or more [12], indicating minimal evaporation during the course of the measurement. All set time measurements were conducted inside a walkin environmental chamber maintained at $(25.0 \pm 1.0){ }^{\circ} \mathrm{C}$. In the ASTM C191 standard [8], the single laboratory precisions are listed as $12 \mathrm{~min}$ and $20 \mathrm{~min}$ for initial and final times of setting, respectively. 


\section{Results}

\subsection{Isothermal Calorimetry}

The typical variability between the two isothermal calorimetry specimens was quite low. Representative plots from two of the mortar mixtures (\#9 and \#18) shown in Figure 3 show that the two curves are basically indistinguishable from one another, as is generally observed when performing this measurement $[4,13]$.
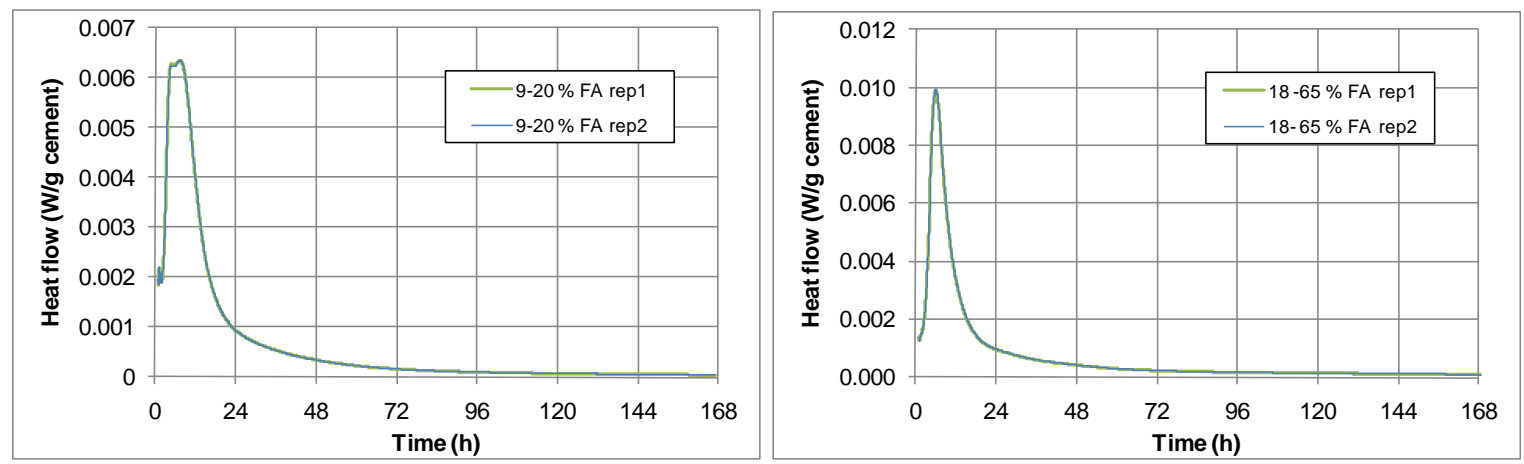

Figure 3. Isothermal calorimetry results for mortar mixtures \#9 (left) and \#18 (right) indicating excellent repeatability between the two replicates in each case.

Heat flow results such as those in Figure 3 can be readily integrated and normalized to produce plots of cumulative heat $\left(\mathrm{J} / \mathrm{cm}^{3}\right.$ mortar) for the 20 mixtures. These cumulative heat results for the first $24 \mathrm{~h}$ of curing are provided in two plots in Figure 4. Due to their finer cements, the blended mixtures with $20 \%$ fly ash (\#9, \#13, \#14, and \#17) generally exceed the cumulative heat produced in the control (100\% original cement) mortar, while some of the $35 \%$ fly ash mixtures (\#8 and \#10) approach the control value. The relationship between cumulative heat release and compressive strength development at the early ages of $1 \mathrm{~d}, 3 \mathrm{~d}$, and $7 \mathrm{~d}$ will be explored further later in this report. In comparison to the control mortar, nearly all of the mortars exhibit a mild (on the order of $1 \mathrm{~h}$ to $2 \mathrm{~h}$ ) retardation, with the exception of mortar mixture \#9 that contains $20 \%$ fly ash and the finest cement 10 . This can be observed in the plots by identifying, for example, the time at which a cumulative heat release of $20 \mathrm{~J} / \mathrm{cm}^{3}$ mortar is achieved, nominally $4 \mathrm{~h}$ for the control mortar. Contributors to this mild retardation could include the (pore solution) dilution of the more reactive cement by less reactive fly ash, chemical interactions of the fly ash with the cement reactions, and the addition of the HRWRA, although the latter was selected especially to minimize such effects and some of the mixtures exhibiting retardation in Figure 4 were produced without any HRWRA. These retarding effects are partially offset by the utilization of finer cements, as increasing cement fineness generally accelerates the hydration reactions slightly (on the order of $1 \mathrm{~h}$ for switching from a Type I/II cement to a Type III cement in HVFA mortars, for example [7]). As has been observed in previous studies [7], the Class C fly ash (mixture \#19) exhibited a significant retardation, achieving a cumulative heat release of $20 \mathrm{~J} / \mathrm{cm}^{3}$ mortar only after $6 \mathrm{~h}$. 

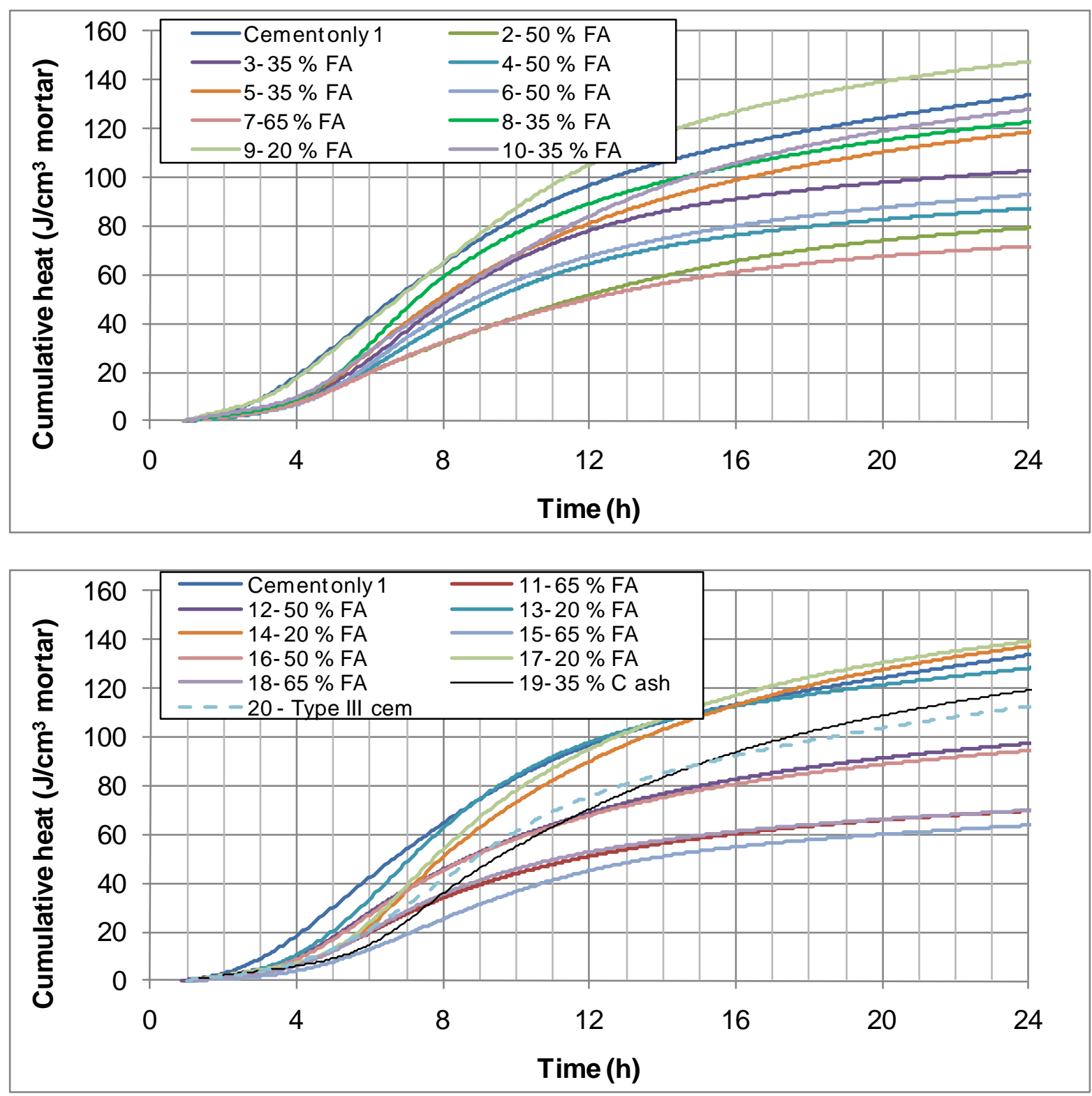

Figure 4. Cumulative heat release curves for the first $24 \mathrm{~h}$ of curing for the 20 mortar mixtures.

\subsection{Setting Times}

Since isothermal calorimetry is a direct indication of the extent of the hydration reactions, but not of the setting process [13], a subset of the mortar mixtures were selected and their component pastes evaluated using the ASTM C191 standard test method for needle penetration [8]. Relative to the control mixture (\#1), the results in Table 4 indicate both minor decreases in setting (\#9) and increases on the order of $1 \mathrm{~h}$ (\#8,\#14). The most extreme delays in setting are observed for mixture \#2, consisting of a 50:50 mixture of the original cement and fly 
ash. As mentioned for the extent of hydration in the previous section, the utilization of a finer cement helps to offset the delays in setting that are typically produced in HVFA mixtures.

Table 4. Setting times (ASTM C191) of pastes from a subset of the mortar mixtures.

\begin{tabular}{|c|c|c|c|c|c|}
\hline $\begin{array}{c}\text { Paste/Mortar } \\
\text { ID }\end{array}$ & Fly ash (\%) & $\begin{array}{c}\text { Cement ID } \\
{\left[\mathrm{D}_{90}\right]}\end{array}$ & $\begin{array}{c}\text { Fly ash ID } \\
{\left[\mathrm{D}_{10}\right]}\end{array}$ & Initial set & Final set \\
\hline 1 & 0 & $6[36 \mu \mathrm{m}]$ & -- & 168 & 214 \\
\hline 2 & 50 & $6[36 \mu \mathrm{m}]$ & $1[2.7 \mu \mathrm{m}]$ & 258 & 318 \\
\hline 8 & 35 & $9[11 \mu \mathrm{m}]$ & $5[4 \mu \mathrm{m}]$ & 227 & 267 \\
\hline 9 & 20 & $10[9 \mu \mathrm{m}]$ & $5[4 \mu \mathrm{m}]$ & 131 & 168 \\
\hline 14 & 20 & $8[12 \mu \mathrm{m}]$ & $3[13 \mu \mathrm{m}]$ & 220 & 255 \\
\hline
\end{tabular}

\subsection{Semi-adiabatic Calorimetry}

The semi-adiabatic temperature curves for the first $48 \mathrm{~h}$ of curing for each of the 20 mortar mixtures are provided in Figure 5, with a linear regression analysis for the maximum temperature given in Figure 6. By observing the curves themselves and the results of the regression analysis, it is clear that fly ash volume fraction has a major influence on temperature rise as the less reactive fly ash dilutes the more reactive cement, generating less heat and lowering the measured temperature rise. Thus, mixtures with the lowest fly ash content of $20 \%$ (\#9, \#14, and \#17) generally exceed the temperature rise of the control mortar, due to their incorporation of a finer, more reactive cement. Two of the mixtures with $35 \%$ fly ash (\#8 and \#10) approach the temperature rise of the control, while those with either $50 \%$ or $65 \%$ fly ash exhibit much smaller temperature rises. This is in accord with the general practice of employing higher contents of fly ash in mass concrete to limit its temperature rise [5]. According to the regression analysis, cement fineness and fly ash fineness have much smaller influences on the semi-adiabatic response. Because of its greater retardation noted above, the Class $\mathrm{C}$ fly ash mixture \#19 produced a slightly delayed and suppressed temperature peak relative to the mixture \#8 with the same cement and $35 \%$ of a Class F fly ash (which could be a benefit in mass concrete construction). 

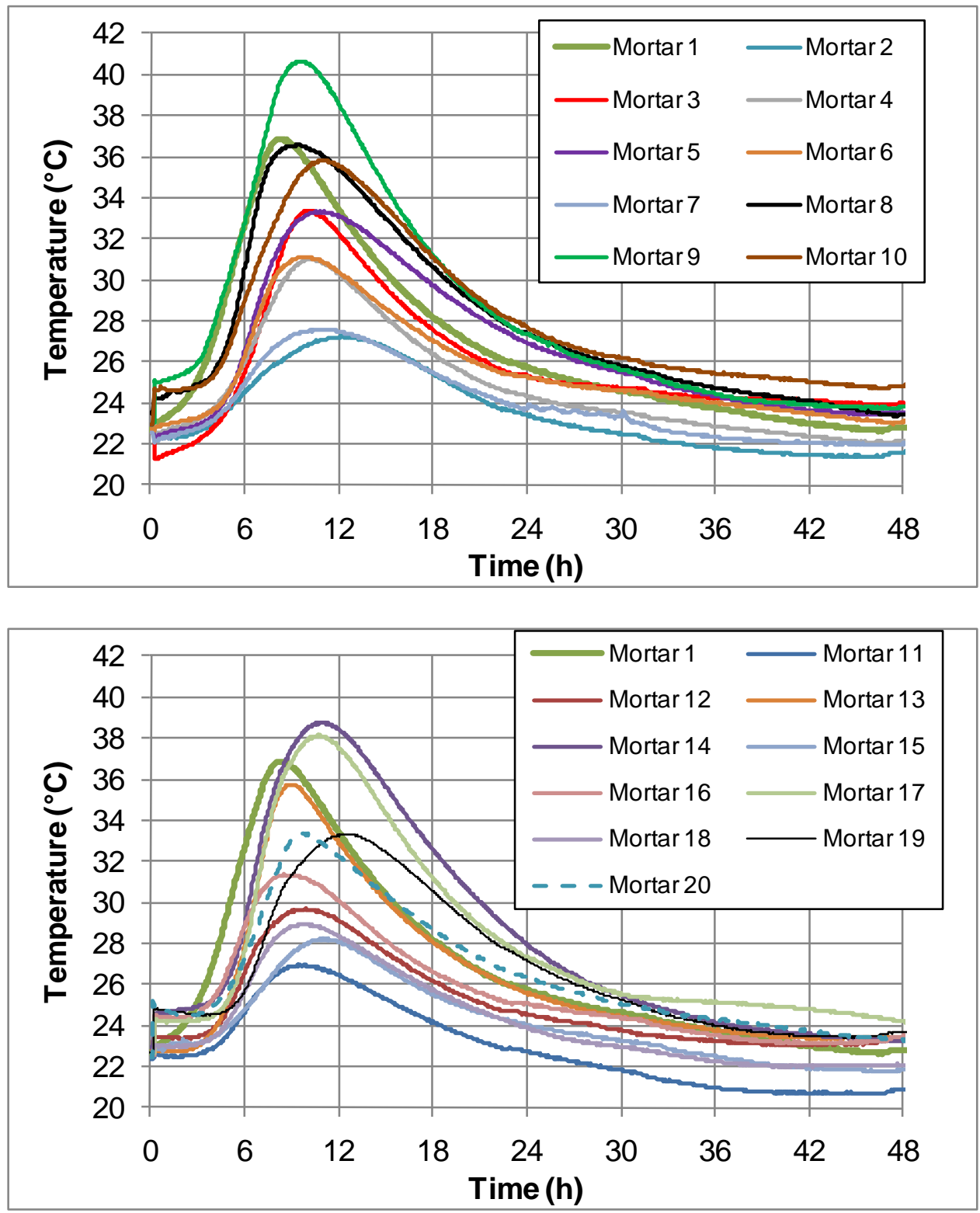

Figure 5. Semi-adiabatic temperature curves for the first $48 \mathrm{~h}$ of curing for the 20 mortar mixtures. 


\begin{tabular}{|c|c|c|c|c|c|c|c|c|}
\hline SUMMARY OUTPUT & & & & & & & & \\
\hline \multicolumn{9}{|c|}{ Regression Statistics } \\
\hline Multiple R & 0.973 & & & & & & & \\
\hline R Square & 0.947 & & & & & & & \\
\hline Adjusted R Square & 0.934 & & & & & & & \\
\hline Standard Uncertainty & 1.099 & & & & & & & \\
\hline Observations & 16 & & & & & & & \\
\hline \multicolumn{9}{|l|}{ ANOVA } \\
\hline & $d f$ & SS & MS & $F$ & Significance $F$ & & & \\
\hline Regression & 3 & 258.670 & 86.223 & 71.440 & $6.367 \mathrm{E}-08$ & & & \\
\hline Residual & 12 & 14.483 & 1.207 & & & & & \\
\hline \multirow[t]{2}{*}{ Total } & 15 & 273.153 & & & & & & \\
\hline & Coefficients & Standard Uncertainty & $t$ Stat & $P$-value & Lower 95\% & Upper 95\% & Lower $95.0 \%$ & Upper $95.0 \%$ \\
\hline Intercept & 44.367 & 1.809 & 24.526 & 1.274E-11 & 40.4253 & 48.3080 & 40.4253 & 48.3080 \\
\hline X Variable 1 & $-2.649 E-03$ & 1.706E-03 & -1.553 & 1.465E-01 & -0.0064 & 0.0011 & -0.0064 & 0.0011 \\
\hline X Variable 2 & 6.010E-03 & 2.306E-03 & 2.606 & 2.296E-02 & 0.0010 & 0.0110 & 0.0010 & 0.0110 \\
\hline X Variable 3 & -0.235 & 0.016 & -14.322 & 6.589E-09 & -0.2702 & -0.1989 & -0.2702 & -0.1989 \\
\hline
\end{tabular}

Figure 6. Regression analysis for maximum temperature vs. cement surface area (X variable 1$)$, fly ash surface area (X variable 2$)$, and fly ash volume fraction in percent (X variable 3$)$.

\subsection{Compressive Strength Testing of Mortar Cubes ${ }^{4}$}

The measured compressive strength test results (means and standard deviations) are detailed in Appendix B. Bar charts for the measured mean strengths for the 20 mixtures at ages of $1 \mathrm{~d}$ and $3 \mathrm{~d}, 7 \mathrm{~d}$ and $28 \mathrm{~d}$, and $91 \mathrm{~d}$ and $182 \mathrm{~d}$ are provided below in Figures 7, 8, and 9, respectively. A major goal of the current project was to produce a blended cement mortar with equivalent or superior $1 \mathrm{~d}$ and $28 \mathrm{~d}$ compressive strengths when compared with the control mortar, all prepared with an equal volume fraction of water. Clearly, most of the blended cements prepared with $20 \%$ fly ash achieved this goal. For a $35 \%$ fly ash replacement, only the more reactive (unclassified) Class $\mathrm{C}$ fly ash was able to produce a mortar satisfying this objective. It is worth noting that at the latest evaluation age of $182 \mathrm{~d}$, several of the $35 \%$ (Class F and Class C) fly ash mortars achieved or exceeded the strength measured on the control mortar.

In contrast to mixture \#20 that was prepared with a commercially available Type III cement and $35 \%$ fly ash, the mixtures prepared with $35 \%$ fly ash and cements \#8, \#9, or \#10 provided higher compressive strengths, while that prepared with cement \#7 failed to achieve the strengths provided by the Type III mixture (\#20). As can be seen in Table 2, cements \#8, \#9, and \#10 indeed have a higher fineness than the Type III cement (Blaine value of $613 \mathrm{~m}^{2} / \mathrm{kg}$ ), while cement \#7 is likely slightly coarser than the Type III cement, taking into account the differences between PSD-estimated and Blaine finenesses, as demonstrated for the original cement in this study $\left(485 \mathrm{~m}^{2} / \mathrm{kg}\right.$ vs. $\left.386 \mathrm{~m}^{2} / \mathrm{kg}\right)$.

\footnotetext{
${ }^{4}$ In this report, all strength results are reported in the non-SI units of psi, as these are the units commonly employed and best recognized by the U.S. construction industry (1000 psi=6.895 MPa).
} 


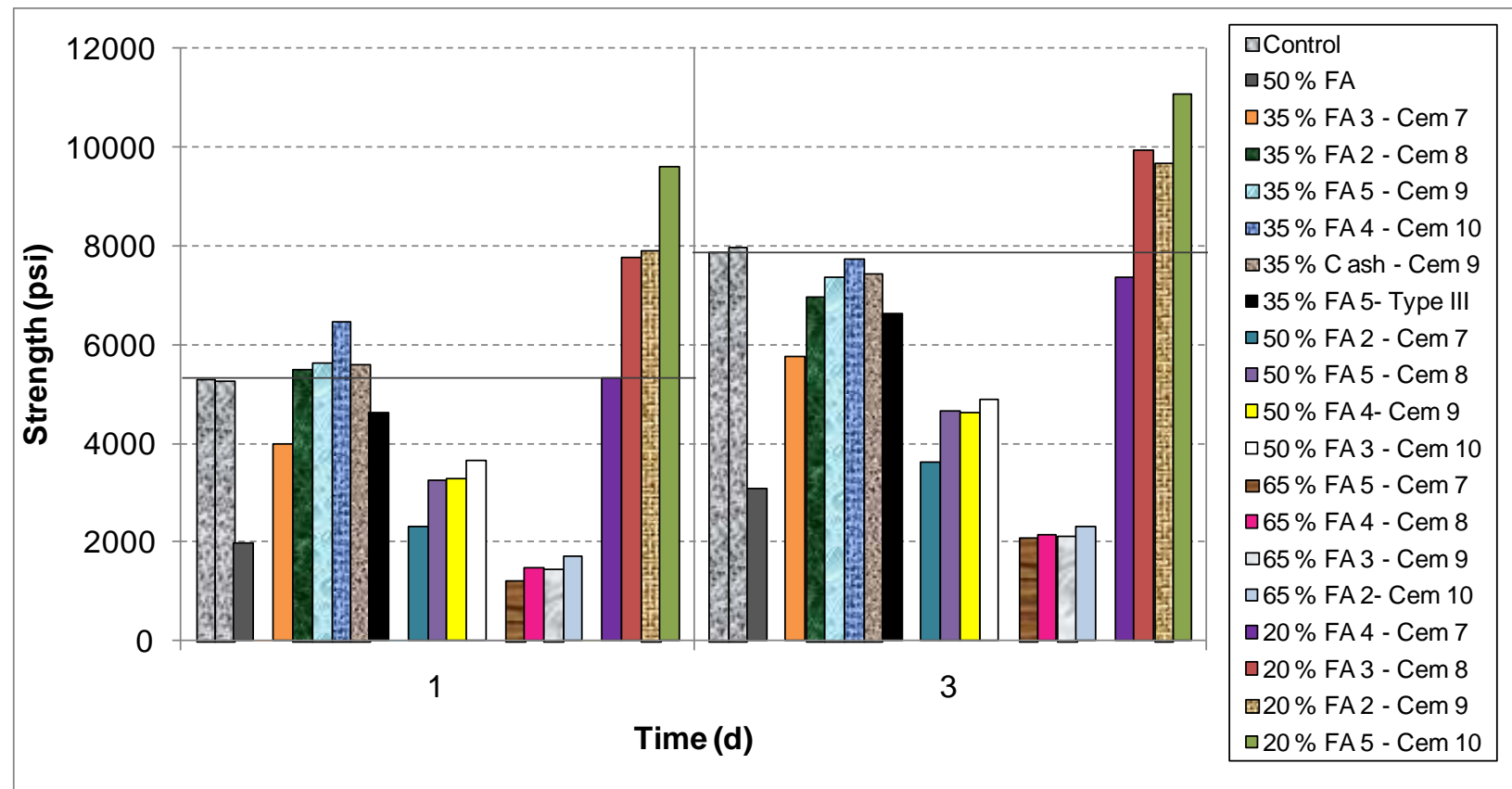

Figure 7. One-day and 3-d mean compressive strengths for the 20 mortar mixtures investigated in the current study. Standard deviations are provided in Appendix B.

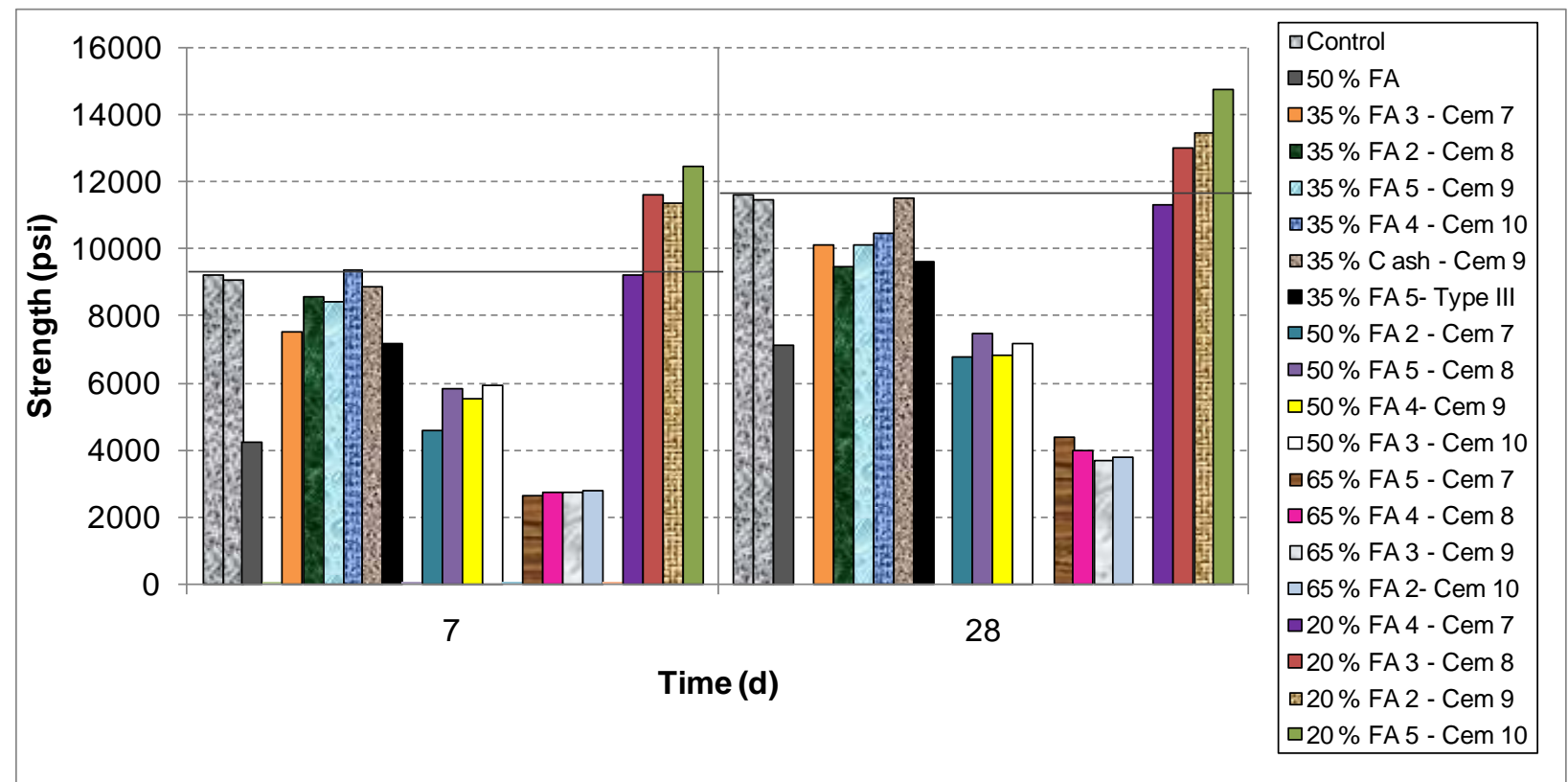

Figure 8. Seven-day and 28-d mean compressive strengths for the $\mathbf{2 0}$ mortar mixtures investigated in the current study. Standard deviations are provided in Appendix B. 


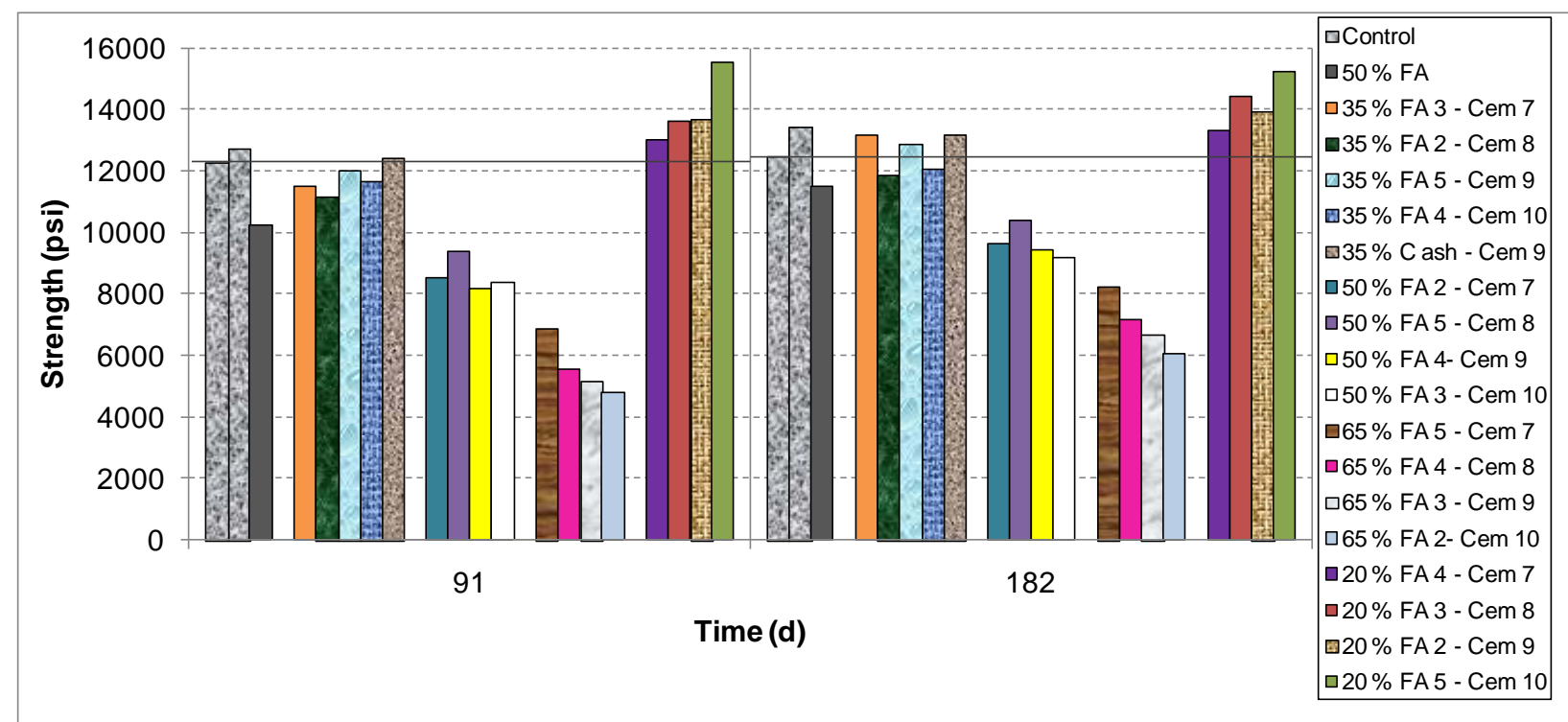

Figure 9. 91-d and 182-d mean compressive strengths for the 20 mortar mixtures investigated in the current study. Standard deviations are provided in Appendix B.

For each of the ages at which strength testing was conducted, graphical and regression analysis results are presented, followed by a brief discussion of these results. The design of experiment (DEX) arithmetic mean plots shown in the figures represent the mean values of the measured strengths for each of the three variables at each of the four levels investigated in the study. These plots clearly indicate the magnitude of any influence each variable has on the compressive strength at a given age. To quantify these influences, linear regression analysis was conducted to determine equations representing the best-fit relationships between the independent variables (cement surface area, fly ash surface area, and fly ash volumetric proportion) and the dependent response (compressive strength at a given age). The regression analyses presented in the following figures are those obtained after first discarding any of the independent variables that do not have a significant influence on strength at a given age. For example, fly ash surface area did not exhibit a significant influence on measured strength at the ages of $1 \mathrm{~d}, 3 \mathrm{~d}$, and $7 \mathrm{~d}$, while cement surface area was not significant at an age of $91 \mathrm{~d}$. For each age, the best fit to the experimental data (lowest standard uncertainty) was obtained by using the PSD-estimated surface areas of the cement and fly ash as independent variables, as opposed to either the targeted $\mathrm{D}_{90}$ and $\mathrm{D}_{10}$ values or the measured $\mathrm{D}_{90}$ and $\mathrm{D}_{10}$ values.

For each age, a second set of regression analyses was conducted using the following equation, containing the absolute surface areas of the cement and fly ash in each mixture:

$$
\sigma(t)=\mathrm{A}_{t}+\mathrm{B}_{t} * \mathrm{CSA} * \rho_{\mathrm{cem}} *(1-\mathrm{FA} / 100)+\mathrm{C}_{t} * \mathrm{FASA} * \rho_{\mathrm{FA}} *(\mathrm{FA} / 100)+\mathrm{D}_{t} * \mathrm{FA}
$$

where $\sigma(t)$ is the compressive strength at time $t$, CSA is the cement surface area, $\rho_{\text {cem }}$ is the specific gravity of the cement (3.2), FASA is the fly ash surface area, $\rho_{\mathrm{FA}}$ is the specific gravity of the fly ash (2.3), FA is the fly ash volume fraction in percent, and $A_{t}, B_{t}, C_{t}$, and $D_{t}$ are the regression coefficients. In general, this model provided slightly improved fits (higher $\mathrm{R}$ ) relative to those obtained using only the three primary independent variables, particularly at early ages. 
Compressive strength at $1 d$

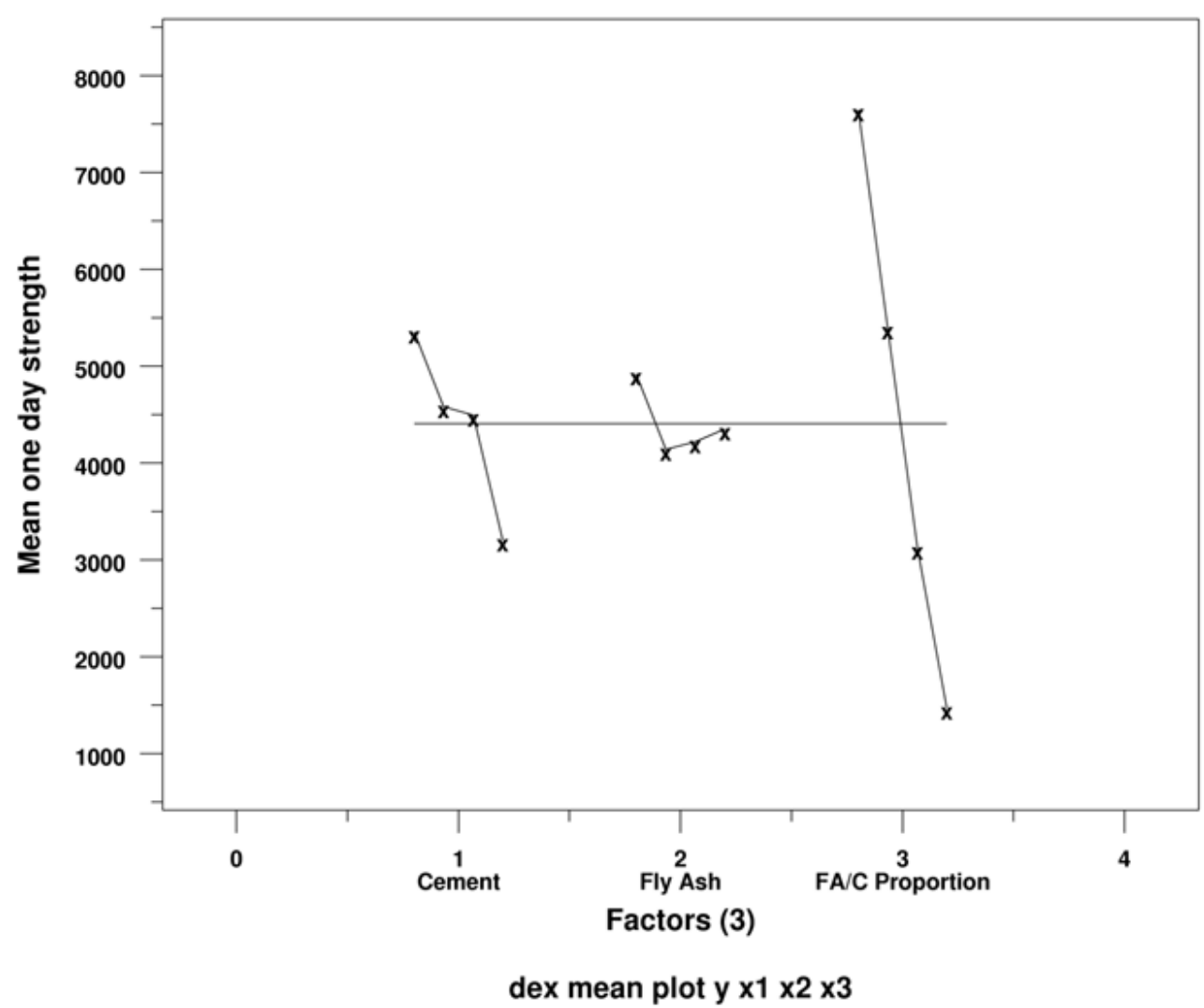

Figure 10. Mean compressive strength at $1 \mathrm{~d}$ vs. the three factors of cement PSD, fly ash PSD, and fly ash volumetric proportion.

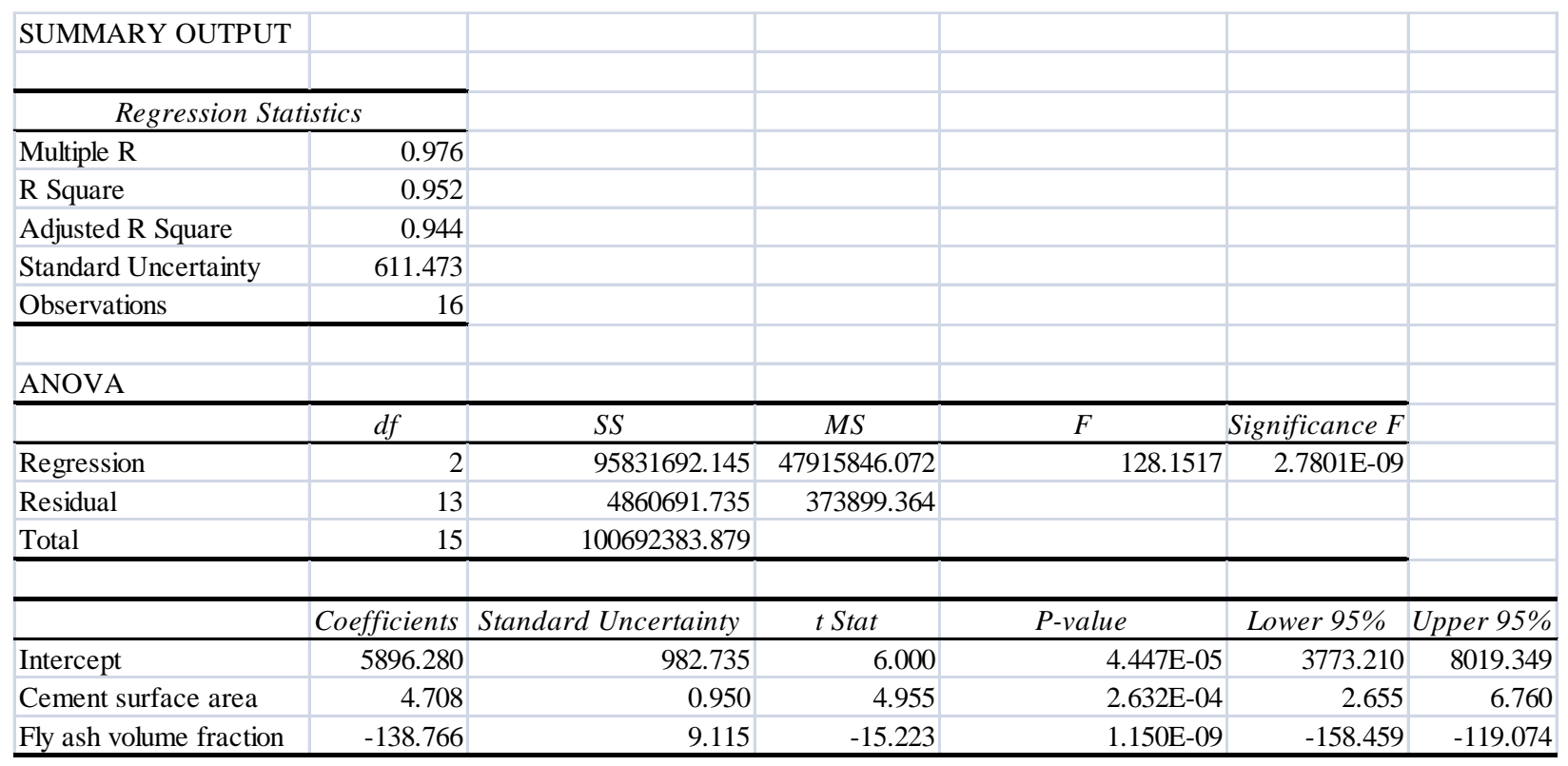

Figure 11. Regression analysis for strength at $1 \mathrm{~d}$ vs. cement surface area and fly ash volume fraction in percent. 


\begin{tabular}{|c|c|c|c|c|c|c|}
\hline SUMMARY OUTPU & & & & & & \\
\hline \multicolumn{7}{|c|}{ Regression Statistics } \\
\hline Multiple R & 0.991 & & & & & \\
\hline R Square & 0.982 & & & & & \\
\hline Adjusted R Square & 0.978 & & & & & \\
\hline Standard Uncertainty & 386.117 & & & & & \\
\hline Observations & 16 & & & & & \\
\hline \multicolumn{7}{|l|}{ ANOVA } \\
\hline & $d f$ & SS & $M S$ & $F$ & Significance F & \\
\hline Regression & 3 & 98903348.33 & 32967782.78 & 221.132 & $9.155 \mathrm{E}-11$ & \\
\hline Residual & 12 & 1789035.546 & 149086.295 & & & \\
\hline \multirow[t]{2}{*}{ Total } & 15 & 100692383.9 & & & & \\
\hline & Coefficients & Standard Uncertainty & $t$ Stat & $P$-value & Lower 95\% & Upper $95 \%$ \\
\hline$A_{t}$ & 1874.607 & 975.002 & 1.923 & 0.0786 & -249.740 & 3998.954 \\
\hline $\mathrm{B}_{\mathrm{t}}$ & 2.813 & 0.313 & 8.981 & 1.129E-06 & 2.130 & 3.495 \\
\hline $\mathrm{C}_{\mathrm{t}}$ & 1.163 & 0.772 & 1.507 & 0.1576 & -0.518 & 2.844 \\
\hline $\mathrm{D}_{\mathrm{t}}$ & -59.076 & 11.355 & -5.203 & 0.00022 & -83.817 & -34.336 \\
\hline
\end{tabular}

Figure 12. Regression analysis for strength at $1 \mathrm{~d}$ according to equation 1.

Compressive strength at $3 d$

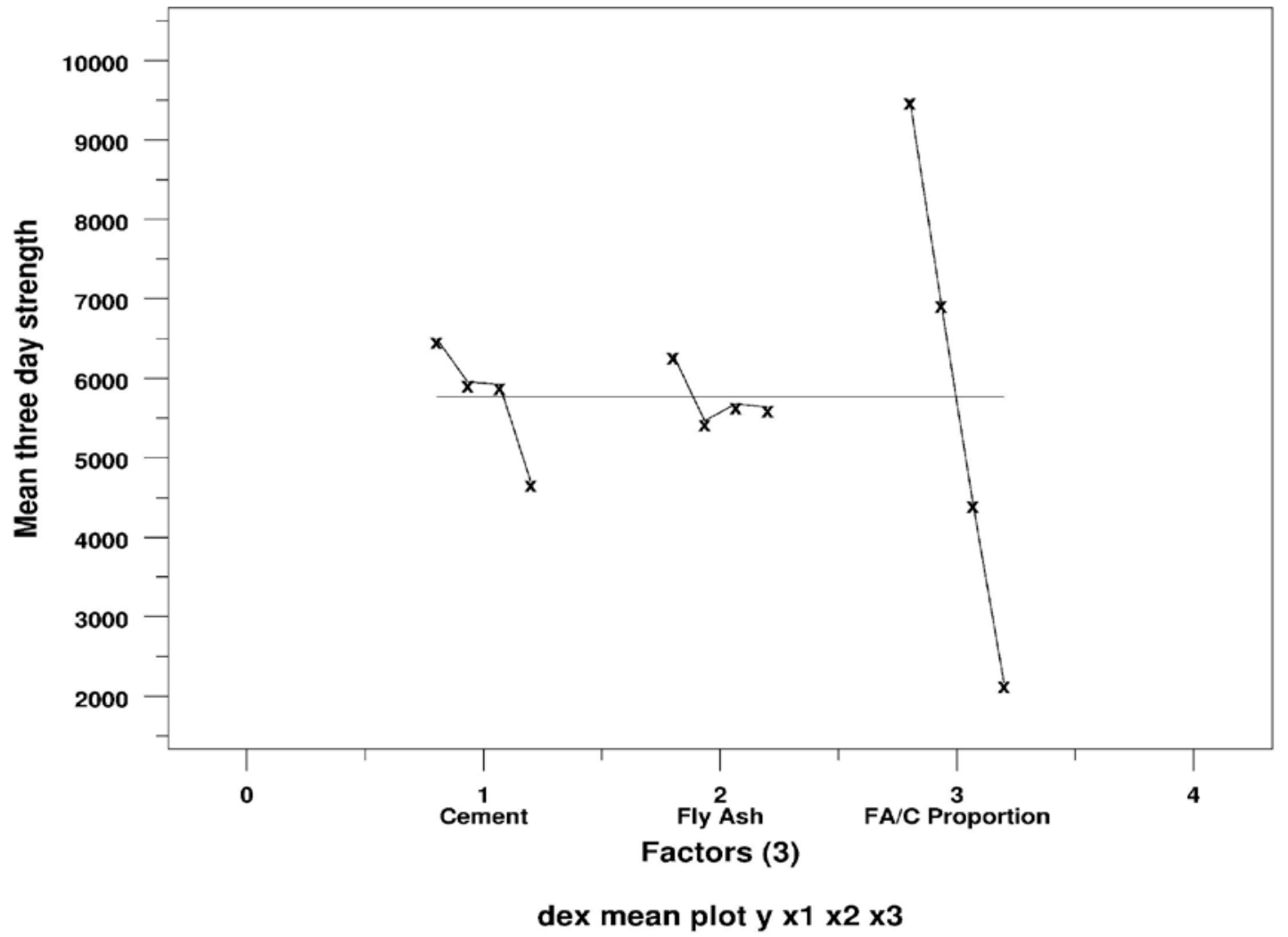

Figure 13. Mean compressive strength at $3 \mathrm{~d}$ vs. the three factors of cement PSD, fly ash PSD, and fly ash volumetric proportion. 


\begin{tabular}{|c|c|c|c|c|c|c|}
\hline SUMMARY OUTPUT & & & & & & \\
\hline \multicolumn{7}{|c|}{ Regression Statistics } \\
\hline Multiple R & 0.985 & & & & & \\
\hline R Square & 0.971 & & & & & \\
\hline Adjusted R Square & 0.966 & & & & & \\
\hline Standard Uncertainty & 542.697 & & & & & \\
\hline Observations & 16 & & & & & \\
\hline \multicolumn{7}{|l|}{ ANOVA } \\
\hline & $d f$ & $S S$ & $M S$ & $F$ & Significance $F$ & \\
\hline Regression & 2 & 127153255.207 & 63576627.603 & 215.865 & 1.067E-10 & \\
\hline Residual & 13 & 3828766.153 & 294520.473 & & & \\
\hline \multirow[t]{2}{*}{ Total } & 15 & 130982021.360 & & & & \\
\hline & Coefficients & Standard Uncertainty & $t$ Stat & P-value & Lower 95\% & Upper 95\% \\
\hline Intercept & 8936.524 & 872.201 & 10.246 & $1.356 \mathrm{E}-07$ & 7052.248 & 10820.801 \\
\hline Cement surface area & 4.042 & 0.843 & 4.794 & 3.506E-04 & 2.221 & 5.864 \\
\hline Fly ash volume fraction & -163.561 & 8.090 & -20.217 & 3.314E-11 & -181.038 & -146.083 \\
\hline
\end{tabular}

Figure 14. Regression analysis for strength at $3 \mathrm{~d}$ vs. cement surface area and fly ash volume fraction in percent.

\begin{tabular}{|c|c|c|c|c|c|c|}
\hline SUMMARY OUTPU' & & & & & & \\
\hline \multicolumn{7}{|c|}{ Regression Statistics } \\
\hline Multiple R & 0.996 & & & & & \\
\hline R Square & 0.992 & & & & & \\
\hline Adjusted R Square & 0.990 & & & & & \\
\hline Standard Uncertainty & 288.204 & & & & & \\
\hline Observations & 16 & & & & & \\
\hline \multicolumn{7}{|l|}{ ANOVA } \\
\hline & $d f$ & $S S$ & $M S$ & $F$ & Significance F & \\
\hline Regression & 3 & 129985286 & 43328428.68 & 521.644 & $5.676 \mathrm{E}-13$ & \\
\hline Residual & 12 & 996735.3314 & 83061.278 & & & \\
\hline \multirow[t]{2}{*}{ Total } & 15 & 130982021.4 & & & & \\
\hline & Coefficients & Standard Uncertainty & $t$ Stat & P-value & Lower 95\% & Upper 95\% \\
\hline$A_{t}$ & 5366.975 & 727.756 & 7.375 & 8.563E-06 & 3781.331 & 6952.620 \\
\hline $\mathrm{B}_{\mathrm{t}}$ & 2.454 & 0.234 & 10.498 & 2.113E-07 & 1.945 & 2.963 \\
\hline $\mathrm{C}_{\mathrm{t}}$ & 1.522 & 0.576 & 2.643 & 0.0215 & 0.267 & 2.777 \\
\hline $\mathrm{D}_{\mathrm{t}}$ & -96.053 & 8.475 & -11.333 & $9.120 \mathrm{E}-08$ & -114.519 & -77.587 \\
\hline
\end{tabular}

Figure 15. Regression analysis for strength at $3 \mathbf{d}$ according to equation (1). 
Compressive strength at $7 d$

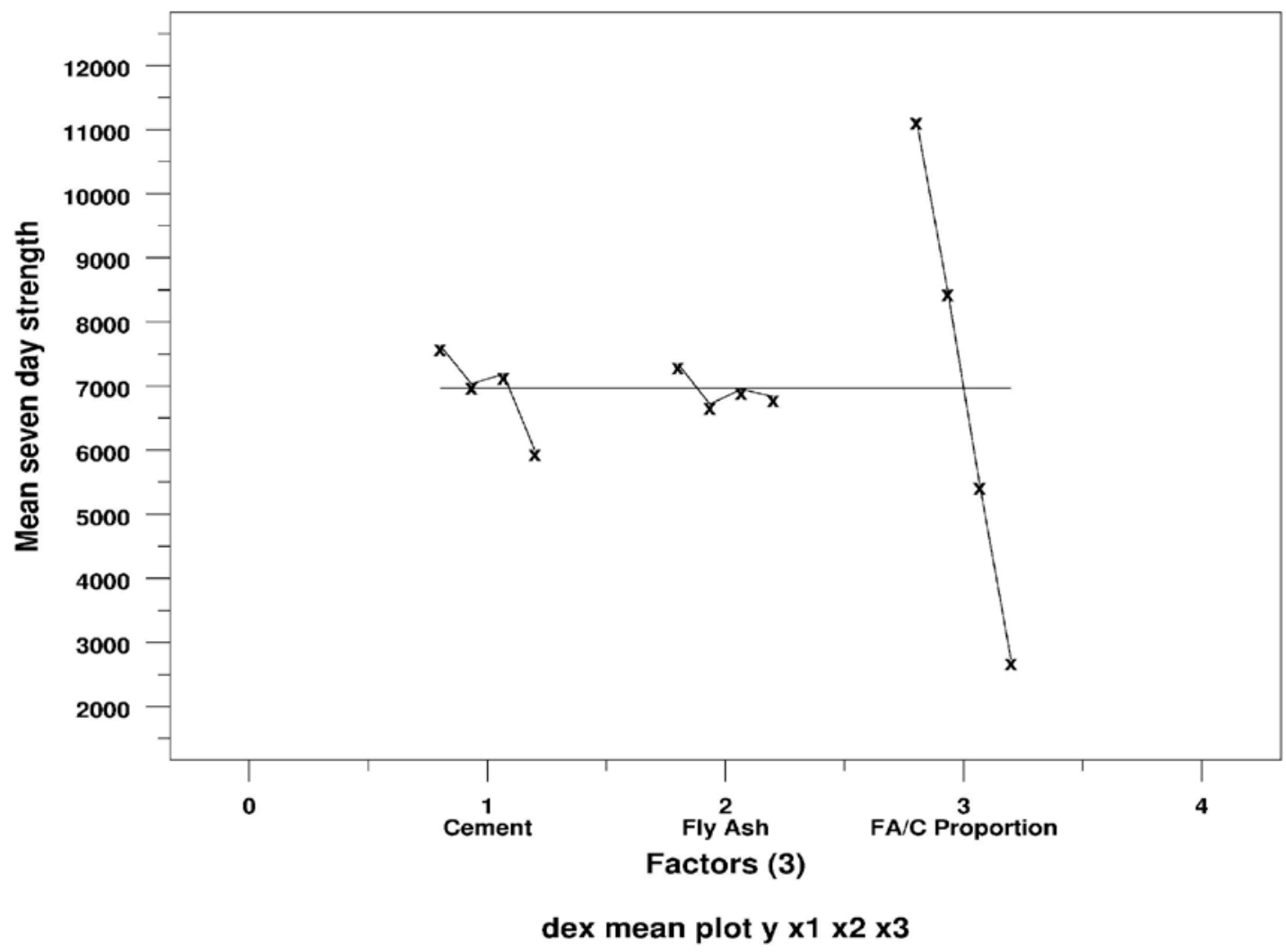

Figure 16 . Mean compressive strength at $7 \mathrm{~d}$ vs. the three factors of cement PSD, fly ash PSD, and fly ash volumetric proportion.

\begin{tabular}{|c|c|c|c|c|c|c|}
\hline \multicolumn{7}{|l|}{ SUMMARY OUTPUT } \\
\hline \multicolumn{7}{|c|}{ Regression Statistics } \\
\hline Multiple R & 0.990 & & & & & \\
\hline R Square & 0.981 & & & & & \\
\hline Adjusted R Square & 0.978 & & & & & \\
\hline Standard Uncertainty & 496.773 & & & & & \\
\hline Observations & 16 & & & & & \\
\hline \multicolumn{7}{|l|}{ ANOVA } \\
\hline & $d f$ & SS & $M S$ & $F$ & Significance $F$ & \\
\hline Regression & 2 & 165964808.925 & 82982404.462 & 336.256 & 6.405E-12 & \\
\hline Residual & 13 & 3208185.240 & 246783.480 & & & \\
\hline \multirow[t]{2}{*}{ Total } & 15 & 169172994.164 & & & & \\
\hline & Coefficients & Standard Uncertainty & $t$ Stat & $P$-value & Lower 95\% & Upper $95 \%$ \\
\hline Intercept & 11577.189 & 798.394 & 14.501 & 2.095E-09 & 9852.365 & 13302.014 \\
\hline Cement surface area & 3.644 & 0.772 & 4.721 & 4.000E-04 & 1.976 & 5.311 \\
\hline Fly ash volume fraction & -188.836 & 7.405 & -25.500 & $1.738 \mathrm{E}-12$ & -204.834 & -172.837 \\
\hline
\end{tabular}

Figure 17. Regression analysis for strength at $7 \mathrm{~d}$ vs. cement surface area and fly ash volume fraction in percent. 


\begin{tabular}{|c|c|c|c|c|c|c|}
\hline SUMMARY OUTPUT & & & & & & \\
\hline \multicolumn{7}{|c|}{ Regression Statistics } \\
\hline Multiple R & 0.997 & & & & & \\
\hline R Square & 0.993 & & & & & \\
\hline Adjusted R Square & 0.991 & & & & & \\
\hline Standard Uncertainty & 310.358 & & & & & \\
\hline Observations & 16 & & & & & \\
\hline \multicolumn{7}{|l|}{ ANOVA } \\
\hline & $d f$ & SS & $M S$ & $F$ & Significance F & \\
\hline Regression & 3 & 168017130.3 & 56005710.08 & 581.443 & $2.975 \mathrm{E}-13$ & \\
\hline Residual & 12 & 1155863.912 & 96321.993 & & & \\
\hline \multirow[t]{2}{*}{ Total } & 15 & 169172994.2 & & & & \\
\hline & Coefficients & Standard Uncertainty & $t$ Stat & P-value & Lower 95\% & Upper 95\% \\
\hline$A_{t}$ & 8407.477 & 783.699 & 10.728 & $1.668 \mathrm{E}-07$ & 6699.944 & 10115.011 \\
\hline $\mathrm{B}_{\mathrm{t}}$ & 2.196 & 0.252 & 8.724 & $1.533 \mathrm{E}-06$ & 1.647 & 2.744 \\
\hline $\mathrm{C}_{\mathrm{t}}$ & 1.107 & 0.620 & 1.784 & 0.0997 & -0.245 & 2.458 \\
\hline $\mathrm{D}_{\mathrm{t}}$ & -127.408 & 9.127 & -13.959 & 8.817E-09 & -147.294 & -107.522 \\
\hline
\end{tabular}

Figure 18. Regression analysis for strength at $7 \mathrm{~d}$ according to equation (1).

Compressive strength at $28 d$

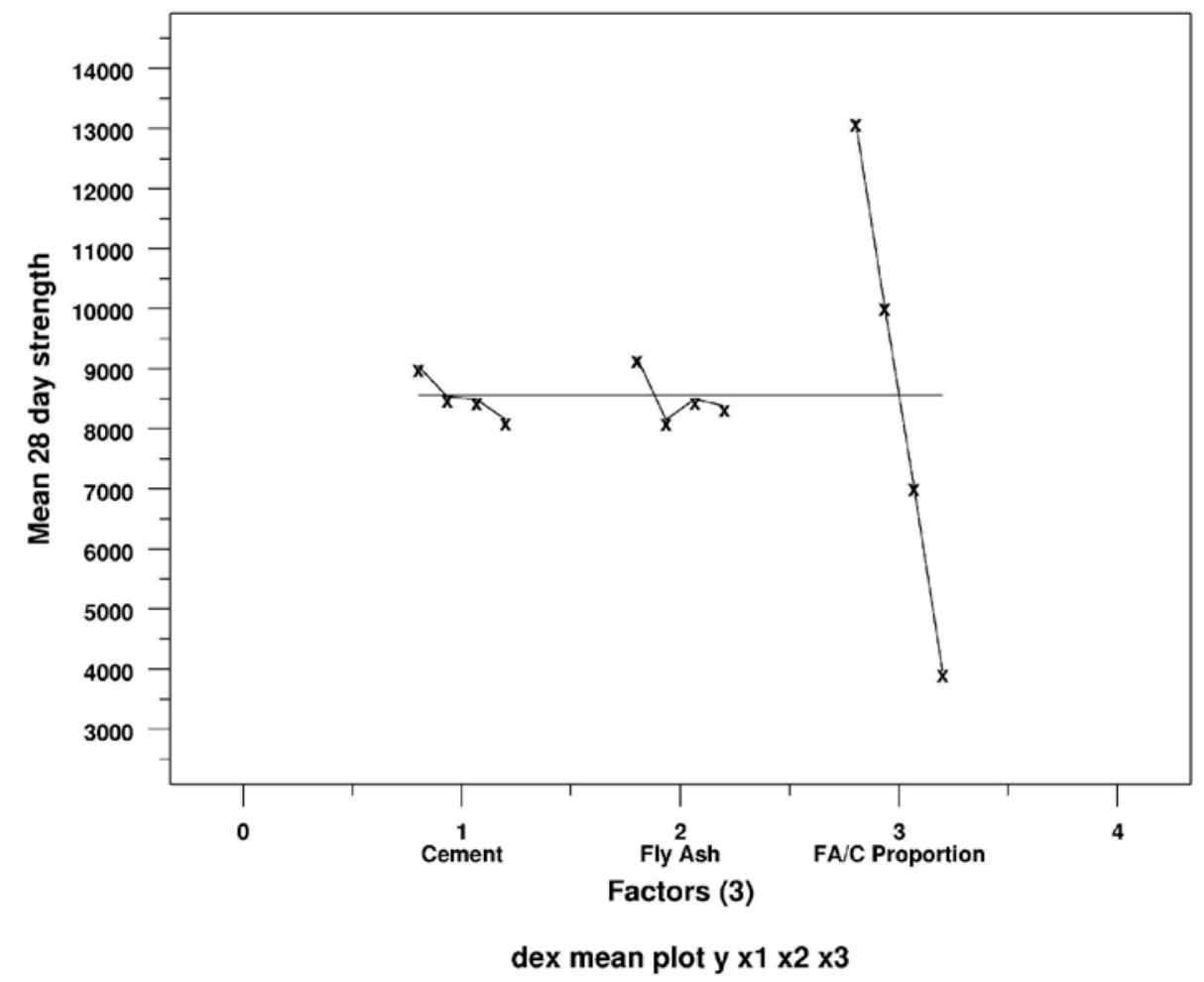

Figure 19. Mean compressive strength at $28 \mathrm{~d}$ vs. the three factors of cement PSD, fly ash PSD, and fly ash volumetric proportion. 


\begin{tabular}{|c|c|c|c|c|c|c|}
\hline SUMMARY OUTPUT & & & & & & \\
\hline \multicolumn{7}{|c|}{ Regression Statistics } \\
\hline Multiple R & 0.990 & & & & & \\
\hline R Square & 0.981 & & & & & \\
\hline Adjusted R Square & 0.976 & & & & & \\
\hline Standard Uncertainty & 559.987 & & & & & \\
\hline Observations & 16 & & & & & \\
\hline \multicolumn{7}{|l|}{ ANOVA } \\
\hline & $d f$ & SS & $M S$ & $F$ & Significance $F$ & \\
\hline Regression & 3 & 189354332.018 & 63118110.673 & 201.279 & $1.592 \mathrm{E}-10$ & \\
\hline Residual & 12 & 3763029.087 & 313585.757 & & & \\
\hline \multirow[t]{2}{*}{ Total } & 15 & 193117361.104 & & & & \\
\hline & Coefficients & Standard Uncertainty & $t$ Stat & P-value & Lower 95\% & Upper 95\% \\
\hline Intercept & 15046.876 & 922.708 & 16.307 & $1.489 \mathrm{E}-09$ & 13036.467 & 17057.284 \\
\hline Cement surface area & 1.736 & 0.870 & 1.995 & 6.928E-02 & -0.160 & 3.631 \\
\hline Fly ash volume fraction & -203.306 & 8.348 & -24.354 & $1.384 \mathrm{E}-11$ & -221.494 & -185.117 \\
\hline Fly ash surface area & 3.047 & 1.175 & 2.592 & 2.356E-02 & 0.486 & 5.607 \\
\hline
\end{tabular}

Figure 20. Regression analysis for strength at $28 \mathrm{~d}$ vs. cement surface area, fly ash volume fraction in percent, and fly ash surface area.

\begin{tabular}{|c|c|c|c|c|c|c|}
\hline \multicolumn{7}{|l|}{ SUMMARY OUTPUT } \\
\hline \multicolumn{7}{|c|}{ Regression Statistics } \\
\hline Multiple R & 0.992 & & & & & \\
\hline R Square & 0.983 & & & & & \\
\hline Adjusted R Square & 0.979 & & & & & \\
\hline Standard Uncertainty & 521.599 & & & & & \\
\hline Observations & 16 & & & & & \\
\hline \multicolumn{7}{|l|}{ ANOVA } \\
\hline & $d f$ & SS & MS & $F$ & Significance F & \\
\hline Regression & 3 & 189852576.3 & 63284192 & 232.607 & $6.796 \mathrm{E}-11$ & \\
\hline Residual & 12 & 3264784.832 & 272065.4 & & & \\
\hline \multirow[t]{2}{*}{ Total } & 15 & 193117361.1 & & & & \\
\hline & Coefficients & Standard Uncertainty & t Stat & $P$-value & Lower 95\% & Upper 95\% \\
\hline$A_{t}$ & 13198.679 & 1317.114 & 10.021 & 3.501E-07 & 10328.934 & 16068.423 \\
\hline $\mathrm{B}_{\mathrm{t}}$ & 1.335 & 0.423 & 3.155 & 0.0083 & 0.413 & 2.257 \\
\hline $\mathrm{C}_{\mathrm{t}}$ & 2.239 & 1.042 & 2.148 & 0.0528 & -0.032 & 4.509 \\
\hline $\mathrm{D}_{\mathrm{t}}$ & -172.202 & 15.339 & -11.226 & 1.013E-07 & -205.623 & -138.781 \\
\hline
\end{tabular}

Figure 21. Regression analysis for strength at $28 \mathrm{~d}$ according to equation (1). 
Compressive strength at $91 d$

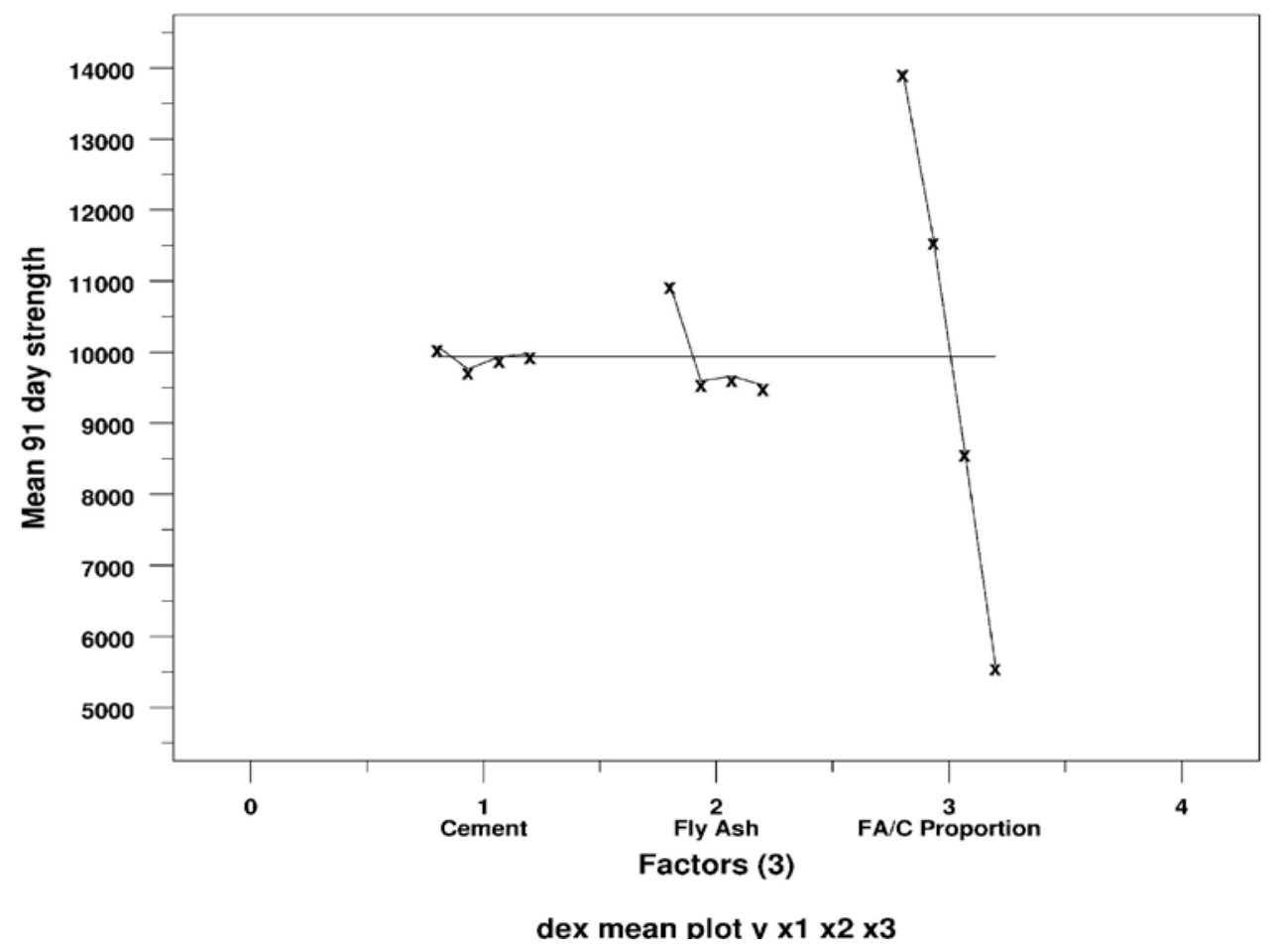

Figure 22. Mean compressive strength at $91 \mathrm{~d}$ vs. the three factors of cement PSD, fly ash PSD, and fly ash volumetric proportion.

\begin{tabular}{|c|c|c|c|c|c|c|}
\hline SUMMARY OUTPUT & & & & & & \\
\hline \multicolumn{7}{|c|}{ Regression Statistics } \\
\hline Multiple R & 0.993 & & & & & \\
\hline R Square & 0.986 & & & & & \\
\hline Adjusted R Square & 0.984 & & & & & \\
\hline Standard Uncertainty & 417.676 & & & & & \\
\hline Observations & 16 & & & & & \\
\hline \multicolumn{7}{|l|}{ ANOVA } \\
\hline & $d f$ & $S S$ & MS & $F$ & Significance F & \\
\hline Regression & 2 & 162929231.901 & 81464615.950 & 466.971 & $7.844 \mathrm{E}-13$ & \\
\hline Residual & 13 & 2267893.517 & 174453.347 & & & \\
\hline \multirow[t]{2}{*}{ Total } & 15 & 165197125.418 & & & & \\
\hline & Coefficients & Standard Uncertainty & t Stat & P-value & Lower 95\% & Upper 95\% \\
\hline Intercept & 17030.992 & 322.435 & 52.820 & $1.474 \mathrm{E}-16$ & 16334.414 & 17727.571 \\
\hline Fly ash volume fraction & -187.001 & 6.226 & -30.034 & $2.141 \mathrm{E}-13$ & -200.452 & -173.550 \\
\hline Fly ash surface area & 4.952 & 0.877 & 5.649 & 7.943E-05 & 3.058 & 6.846 \\
\hline
\end{tabular}

Figure 23. Regression analysis for strength at $91 \mathrm{~d}$ vs. fly ash volume fraction in percent and fly ash surface area. 


\begin{tabular}{|c|c|c|c|c|c|c|}
\hline \multicolumn{7}{|l|}{ SUMMARY OUTPUT } \\
\hline \multicolumn{7}{|c|}{ Regression Statistics } \\
\hline Multiple R & 0.992 & & & & & \\
\hline R Square & 0.983 & & & & & \\
\hline Adjusted R Square & 0.979 & & & & & \\
\hline Standard Uncertainty & 476.787 & & & & & \\
\hline Observations & 16 & & & & & \\
\hline \multirow{2}{*}{\multicolumn{7}{|c|}{ ANOVA }} \\
\hline & & & & & & \\
\hline & $d f$ & $S S$ & $M S$ & $F$ & Significance F & \\
\hline Regression & 3 & 162469215.6 & 54156405 & 238.233 & 5.904E-11 & \\
\hline Residual & 12 & 2727909.776 & 227325.8 & & & \\
\hline \multirow[t]{2}{*}{ Total } & 15 & 165197125.4 & & & & \\
\hline & Coefficients & Standard Uncertainty & t Stat & P-value & Lower 95\% & Upper 95\% \\
\hline$A_{t}$ & 16326.205 & 1203.957 & 13.560 & $1.225 \mathrm{E}-08$ & 13703.008 & 18949.402 \\
\hline $\mathrm{B}_{\mathrm{t}}$ & 0.521 & 0.387 & 1.347 & 0.203 & -0.321 & 1.364 \\
\hline $\mathrm{C}_{\mathrm{t}}$ & 4.367 & 0.953 & 4.584 & 0.00063 & 2.291 & 6.443 \\
\hline $\mathrm{D}_{\mathrm{t}}$ & -188.770 & 14.021 & -13.463 & 1.329E-08 & -219.319 & -158.220 \\
\hline
\end{tabular}

Figure 24. Regression analysis for strength at $91 \mathrm{~d}$ according to equation (1).

Compressive strength at $182 d$

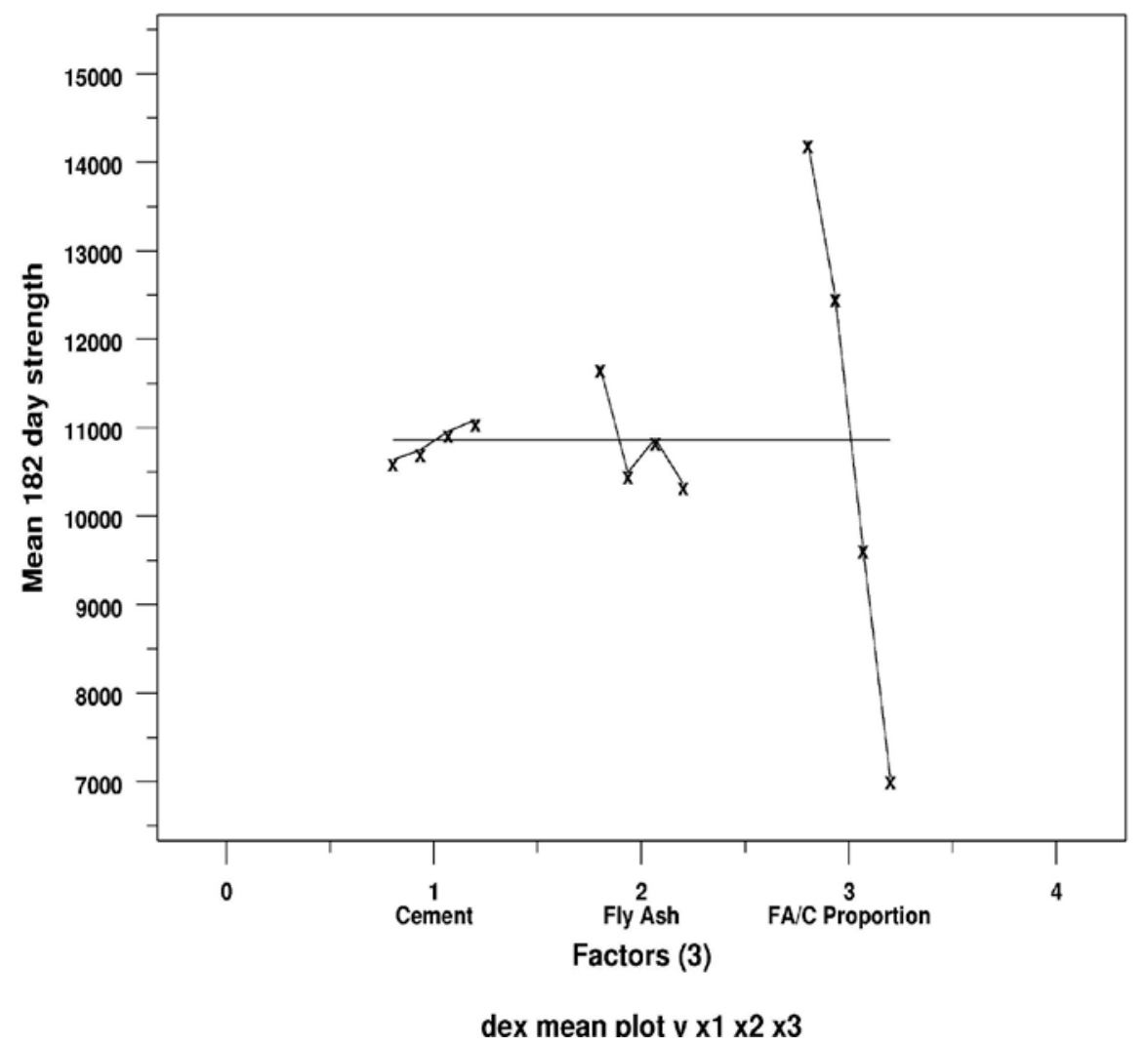

Figure 25. Mean compressive strength at $182 \mathrm{~d}$ vs. the three factors of cement PSD, fly ash PSD, and fly ash volumetric proportion. 


\begin{tabular}{|c|c|c|c|c|c|c|}
\hline SUMMARY OUTPUT & & & & & & \\
\hline \multicolumn{7}{|c|}{ Regression Statistics } \\
\hline Multiple R & 0.985 & & & & & \\
\hline R Square & 0.971 & & & & & \\
\hline Adjusted R Square & 0.964 & & & & & \\
\hline Standard Uncertainty & 554.678 & & & & & \\
\hline Observations & 16 & & & & & \\
\hline \multicolumn{7}{|l|}{ ANOVA } \\
\hline & $d f$ & SS & $M S$ & $F$ & Significance F & \\
\hline Regression & 3 & 123260247.1 & 41086749.05 & 133.5428 & $1.752 \mathrm{E}-09$ & \\
\hline Residual & 12 & 3692007.817 & 307667.318 & & & \\
\hline \multirow[t]{2}{*}{ Total } & 15 & 126952255 & & & & \\
\hline & Coefficients & Standard Uncertainty & $t$ Stat & $P$-value & Lower 95\% & Upper 95\% \\
\hline Intercept & 18012.672 & 913.959 & 19.708 & $1.656 \mathrm{E}-10$ & 16021.325 & 20004.019 \\
\hline Cement surface area & -0.989 & 0.862 & -1.147 & 0.274 & -2.866 & 0.889 \\
\hline Fly ash volume fraction & -162.767 & 8.269 & -19.685 & $1.679 \mathrm{E}-10$ & -180.782 & -144.751 \\
\hline Fly ash surface area & 4.003 & 1.164 & 3.438 & 0.00491 & 1.466 & 6.539 \\
\hline
\end{tabular}

Figure 26. Regression analysis for strength at $182 \mathrm{~d}$ vs. cement surface area, fly ash volume fraction in percent, and fly ash surface area.

\begin{tabular}{|c|c|c|c|c|c|c|}
\hline \multicolumn{7}{|c|}{ SUMMARY OUTPUT } \\
\hline \multicolumn{7}{|c|}{ Regression Statistics } \\
\hline Multiple R & 0.983 & & & & & \\
\hline R Square & 0.967 & & & & & \\
\hline Adjusted R Square & 0.959 & & & & & \\
\hline Standard Uncertainty & 590.562 & & & & & \\
\hline Observations & 16 & & & & & \\
\hline \multicolumn{7}{|l|}{ ANOVA } \\
\hline & $d f$ & $S S$ & $M S$ & $F$ & Significance F & \\
\hline Regression & 3 & 122767087.9 & 40922363 & 117.335 & 3.711E-09 & \\
\hline Residual & 12 & 4185167.063 & 348763.9 & & & \\
\hline \multirow[t]{2}{*}{ Total } & 15 & 126952255 & & & & \\
\hline & Coefficients & Standard Uncertainty & $t$ Stat & P-value & Lower 95\% & Upper 95\% \\
\hline$A_{t}$ & 17928.650 & 1491.257 & 12.023 & 4.736E-08 & 14679.481 & 21177.820 \\
\hline $\mathrm{B}_{\mathrm{t}}$ & -0.050 & 0.479 & -0.104 & 0.919 & -1.093 & 0.994 \\
\hline $\mathrm{C}_{\mathrm{t}}$ & 3.757 & 1.180 & 3.183 & 0.00787 & 1.186 & 6.328 \\
\hline $\mathrm{D}_{\mathrm{t}}$ & -179.219 & 17.367 & -10.319 & 2.547E-07 & -217.059 & -141.380 \\
\hline
\end{tabular}

Figure 27. Regression analysis for strength at $182 \mathrm{~d}$ according to equation (1). 
Table 5. Linear regression coefficients vs. age for compressive strength data for primary independent variables.

\begin{tabular}{|c|c|c|c|c|c|}
\hline \multicolumn{5}{|c|}{ Linear regression coefficients vs. age } & \\
\hline Age (d) & Intercept (psi) & Cement fineness & FA content & FA fineness & $\begin{array}{c}\text { Coefficient of } \\
\text { determination } \\
\left(\mathrm{R}^{2}\right)\end{array}$ \\
\hline 1 & 5900 & 4.71 & -138.8 & --- & 0.952 \\
\hline 3 & 8940 & 4.04 & -163.6 & --- & 0.971 \\
\hline 7 & 11580 & 3.64 & -188.8 & --- & 0.981 \\
\hline 28 & 15050 & 1.74 & -203.3 & 3.05 & 0.981 \\
\hline 91 & 18940 & --- & -187.0 & 4.95 & 0.986 \\
\hline 182 & 18010 & -0.99 & -162.8 & 4.00 & 0.971 \\
\hline
\end{tabular}

Table 6. Linear regression coefficients vs. age for compressive strength data according to equation (1).

\begin{tabular}{|c|c|c|c|c|c|}
\hline \multicolumn{5}{|c|}{ Linear regression coefficients vs. age } & \\
\hline Age (d) & $\begin{array}{c}\text { Intercept - } \mathrm{A}_{\mathrm{t}} \\
(\mathrm{psi})\end{array}$ & $\mathrm{B}_{\mathrm{t}}$ & $\mathrm{C}_{\mathrm{t}}$ & $\mathrm{D}_{\mathrm{t}}$ & $\begin{array}{c}\text { Coefficient of } \\
\text { determination } \\
\left(\mathrm{R}^{2}\right)\end{array}$ \\
\hline 1 & 1875 & 2.81 & 1.16 & -59.1 & 0.982 \\
\hline 3 & 5370 & 2.45 & 1.52 & -96.1 & 0.992 \\
\hline 7 & 8410 & 2.20 & 1.11 & -127.4 & 0.993 \\
\hline 28 & 13200 & 1.34 & 2.24 & -172.2 & 0.983 \\
\hline 91 & 16330 & 0.521 & 4.37 & -188.8 & 0.983 \\
\hline 182 & 17930 & -0.050 & 3.76 & -179.2 & 0.967 \\
\hline
\end{tabular}

The following observations can be made based on the graphical and regression analyses of the compressive strength data (based directly on the regression analyses in Table 5 but consistent with those in Table 6):

1) Fly ash proportion has a major influence on compressive strength values at all ages of testing. While the linear regression coefficients shown in Table 5 indicates a maximum magnitude of the coefficients at a testing age of $28 \mathrm{~d}$, if these coefficients are normalized by the strength values of the control mortar at each age (as indicated by the values in Appendix B), the relative influence of fly ash proportion decreases with age. This indicates that at longer times, fly ash provides strength equivalence to cement, in agreement with general results from the literature.

2) Cement fineness has a significant influence on strength at early ages, was deemed insignificant at a testing age of $91 \mathrm{~d}$ in Table 5 , and once again produced a significant influence but of an opposite sign at $182 \mathrm{~d}$ in Table 5. Producing a finer cement accelerates hydration at early ages, contributing to strength enhancement. At an age of $91 \mathrm{~d}$, however, all of the cements investigated in this study were sufficiently fine to have nearly achieved complete hydration and thus provide nominally equivalent contributions to strength. Finally, at an age of $182 \mathrm{~d}$, the finer cements produced slightly lower strengths. One possible explanation for this might be the 
enhanced micro-reinforcement provided by any remaining unhydrated coarser cement particles relative to their finer counterparts.

3) Conversely, fly ash fineness, while insignificant at testing ages of $1 \mathrm{~d}, 3 \mathrm{~d}$, and $7 \mathrm{~d}$ in Table 5 , has a significant influence on later age strength at $28 \mathrm{~d}$ and beyond, with the regression coefficient varying between about 3 and 5 for the three later testing ages in Table 5. Within the range of sizes investigated in the present study, coarser fly ash particles will not react as readily as finer ones, so that later age strength is best enhanced by finer fly ash particles.

\subsection{Compressive Strength vs. Heat Release Analysis}

Because all of the mortars were prepared with constant volumetric proportions and, therefore, a constant initial volume fraction of water-filled porosity, one could hypothesize the existence of a relationship between hydration as assessed by heat release and strength development [4], since strength development is due to the building of bridges between cement and fly ash particles. This assumes that the initial porosity is the controlling variable for strength development and that interparticle spacing and total particle surface area are secondary influences for the range of mixtures investigated in the present study. It further assumes that the heat release of the cement hydration and fly ash pozzolanic reactions contribute proportionally to reaction product formation and thus strength development. The results plotted in Figure 28 do indeed indicate a fairly linear relationship between these two variables with some scatter, with an $\mathrm{R}^{2}=0.9$ (Figure 29). This relationship spans one order of magnitude in compressive strength values (from 1210 psi to over 12,400 psi), with the predictions exhibiting a standard uncertainty of less than 1000 psi (Figure 29). The results also indicate that for this particular mortar mixture design, a heat release of about $50 \mathrm{~J} / \mathrm{cm}^{3}$ would be required to initiate significant strength development (e.g., after final setting).

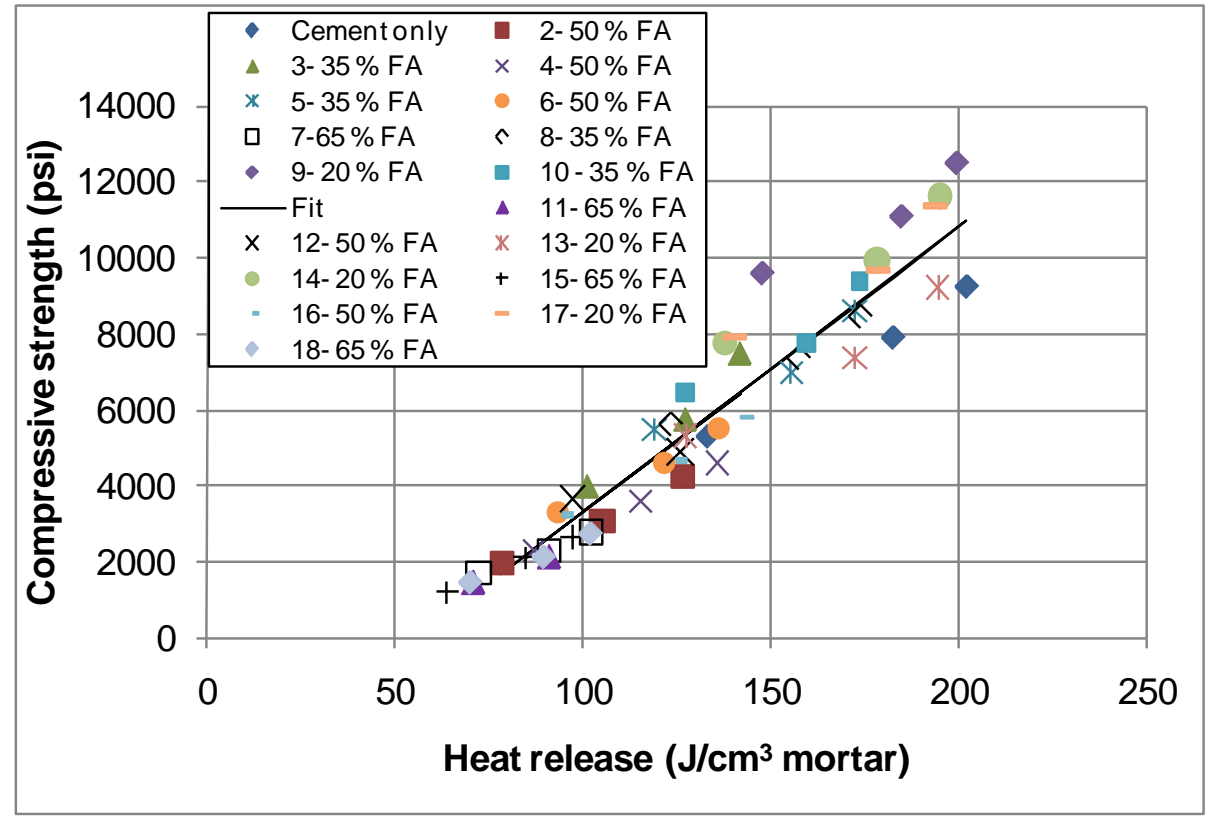

Figure 28. Plot of mean mortar cube compressive strengths vs. heat release for ages of $1 \mathrm{~d}$, $3 \mathrm{~d}$, and $7 \mathrm{~d}$, indicating a generally linear relationship. 


\begin{tabular}{|c|c|c|c|c|c|c|}
\hline \multicolumn{7}{|c|}{ SUMMARY OUTPUT } \\
\hline \multicolumn{7}{|c|}{ Regression Statistics } \\
\hline Multiple R & 0.949 & & & & & \\
\hline R Square & 0.901 & & & & & \\
\hline Adjusted R Square & 0.900 & & & & & \\
\hline Standard Uncertainty & 970.167 & & & & & \\
\hline Observations & 55 & & & & & \\
\hline \multicolumn{7}{|l|}{ ANOVA } \\
\hline & $d f$ & $S S$ & $M S$ & $F$ & Significance F & \\
\hline Regression & 1 & 456167347.519 & $4.562 \mathrm{E}+08$ & 484.653 & $2.480 \mathrm{E}-28$ & \\
\hline Residual & 53 & 49884857.265 & 941223.722 & & & \\
\hline \multirow[t]{2}{*}{ Total } & 54 & 506052204.785 & & & & \\
\hline & Coefficients & Standard Uncertainty & t Stat & P-value & Lower 95\% & Upper 95\% \\
\hline Intercept & -4143.576 & 461.178 & -8.985 & 3.09665E-12 & -5068.581 & -3218.571 \\
\hline $\mathrm{X}$ Variable 1 & 74.888 & 3.402 & 22.015 & $2.47985 \mathrm{E}-28$ & 68.065 & 81.711 \\
\hline
\end{tabular}

Figure 29. Regression analysis for fit of $1 \mathrm{~d}, 3 \mathrm{~d}$, and $7 \mathrm{~d}$ compressive strength vs. cumulative heat release measured at the same ages.

\subsection{Autogenous Deformation}

An indication of typical measurement variability for the autogenous deformation of the corrugated tubes filled with mortar (ASTM C1698 [9]) is provided in Figure 30, which shows the individual and average values for three specimens of mortar mixture \#17. The standard deviation among the three values is in the range of 30 microstrain, in agreement with the precision quoted in the ASTM C1698 test method [9]. Subsequently, each mortar mixture was characterized by the average net autogenous shrinkage measured at $28 \mathrm{~d}$, calculated as the difference between the maximum observed expansion (if any) and the deformation (shrinkage) measured at $28 \mathrm{~d}$, based on the suggested protocol of Cusson [17]. These 28-d net shrinkage values are included in Appendix C, and were used to create DEX mean plots and to perform regression analysis, similar to the analyses conducted for compressive strength at each age. The DEX mean plots and the regression results are provided in Figures 31 and 32, respectively. In Figure 31, the fly ash volumetric proportion has a major influence on autogenous deformation, the cement fineness has a significant effect, and the fly ash fineness has a much smaller influence; this qualitative analysis is confirmed by the quantitative regression coefficients and t-statistics provided in Figure 32. The computed square of the correlation coefficient $\left(\mathrm{R}^{2}=0.87\right)$ is lower for fitting the 28-d net autogenous shrinkage results than it was for any of the six fits of the measured compressive strength data (each $\mathrm{R}^{2}>0.95$ ), as autogenous deformation is also dependent on interparticle pore sizes in addition to reactive surface areas [4,14]. 


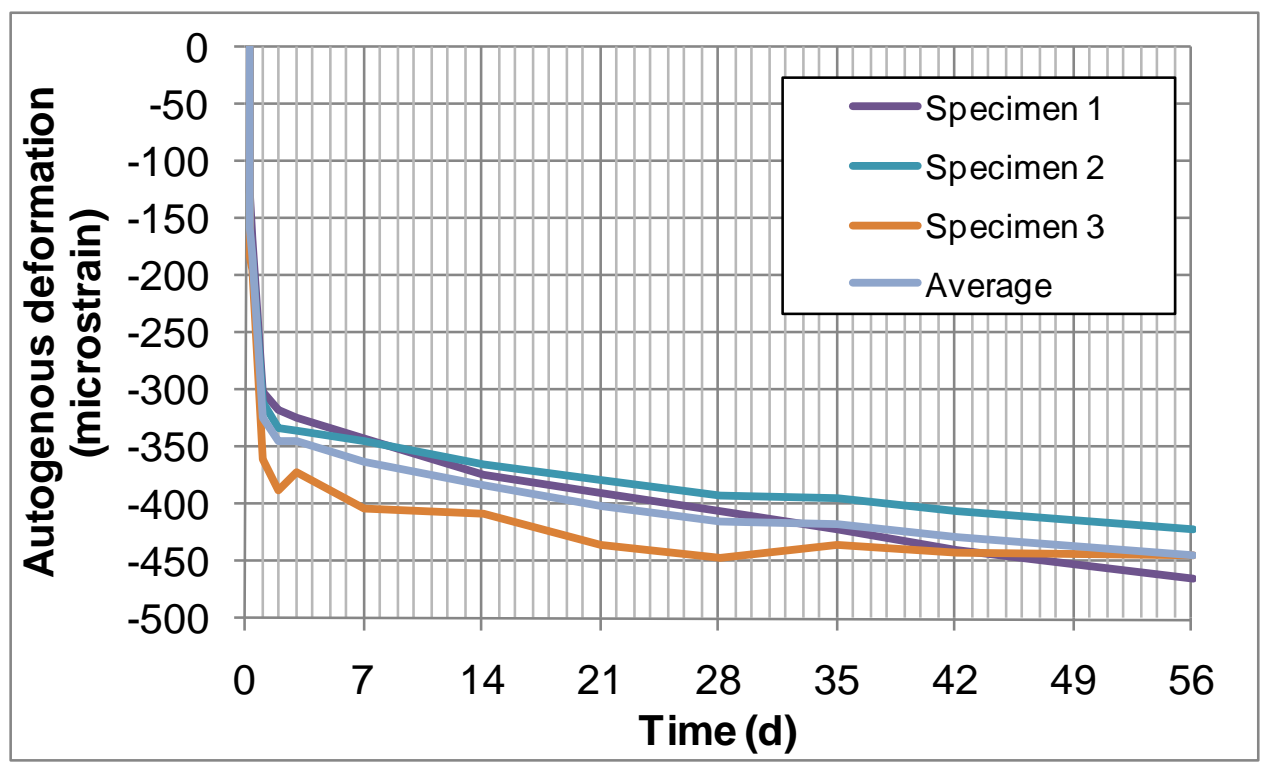

Figure 30. Autogenous deformation measured during the course of $56 \mathbf{d}$ for mortar mixture \#17, providing an indication of typical measurement variability.

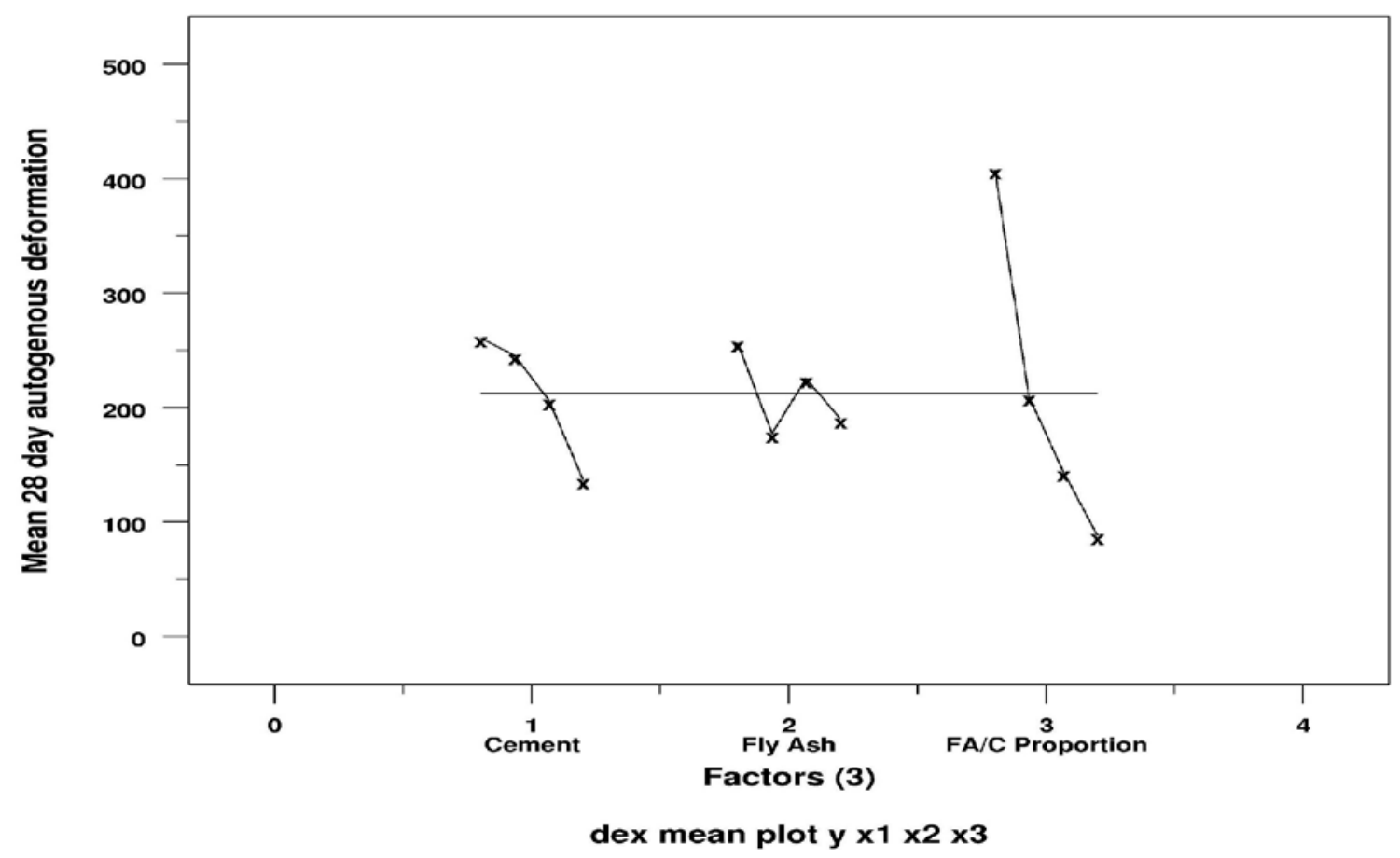

Figure 31. Mean net autogenous shrinkage (deformation) at $28 \mathrm{~d}$ vs. the three factors of cement PSD, fly ash PSD, and fly ash/cement ratio. 


\begin{tabular}{|c|c|c|c|c|c|c|}
\hline \multicolumn{7}{|l|}{ SUMMARY OUTPUT } \\
\hline \multicolumn{7}{|c|}{ Regression Statistics } \\
\hline Multiple R & 0.932 & & & & & \\
\hline R Square & 0.868 & & & & & \\
\hline Adjusted R Square & 0.835 & & & & & \\
\hline Standard Uncertainty & 56.803 & & & & & \\
\hline Observations & 16 & & & & & \\
\hline \multicolumn{7}{|l|}{ ANOVA } \\
\hline & $d f$ & $S S$ & $M S$ & $F$ & Significance F & \\
\hline Regression & 3 & 255227.540 & 85075.847 & 26.368 & 1.443E-05 & \\
\hline Residual & 12 & 38718.468 & 3226.539 & & & \\
\hline \multirow[t]{2}{*}{ Total } & 15 & 293946.009 & & & & \\
\hline & Coefficients & Standard Uncertainty & t Stat & $P$-value & Lower 95\% & Upper 95\% \\
\hline Intercept & 191.969 & 93.595 & 2.051 & $6.276 \mathrm{E}-02$ & -11.958 & 395.896 \\
\hline Cement surface area & 0.293 & 0.088 & 3.322 & $6.087 \mathrm{E}-03$ & 0.101 & 0.485 \\
\hline Fly ash volume fraction & -6.828 & 0.847 & -8.064 & 3.465E-06 & -8.673 & -4.983 \\
\hline Fly ash surface area & 0.208 & 0.119 & 1.743 & $1.068 \mathrm{E}-01$ & -0.052 & 0.468 \\
\hline
\end{tabular}

Figure 32. Regression analysis for net autogenous shrinkage at $28 \mathrm{~d}$ vs. cement surface area, fly ash volume fraction in percent, and fly ash surface area.

\subsection{Autogenous Deformation vs. Strength Analysis}

While strength is determined by the building and reinforcement of "bridges" between the original cement and fly ash particles, autogenous deformation depends both on the size of pores being (partially) emptied due to self-desiccation (as this pore size determines the magnitude of the autogenous stresses) and on the elastic modulus and creep coefficient of the material, as these latter two will determine the mortar's deformation response to this stress level [14]. In general, finer cements will produce increased strengths at early ages due to their increased surface area producing higher hydration rates and will also increase autogenous deformation due to the smaller interparticle spacing (along with the increased hydration rate concurrently increasing chemical shrinkage and the self-desiccation that chemical shrinkage produces). The relationship between net autogenous shrinkage and compressive strength is further explored in Figure 33 that plots the 28-d net autogenous shrinkage vs. the 28-d mortar cube compressive strength for the first 19 of the mortar mixtures. A monotonic (fairly linear) relationship is observed, with significant scatter. The three highest strength mixtures (with $20 \%$ fly ash and the finest three cements) are also those that exhibit net autogenous shrinkages greater than 400 microstrain, and could therefore be more susceptible to early-age cracking. 


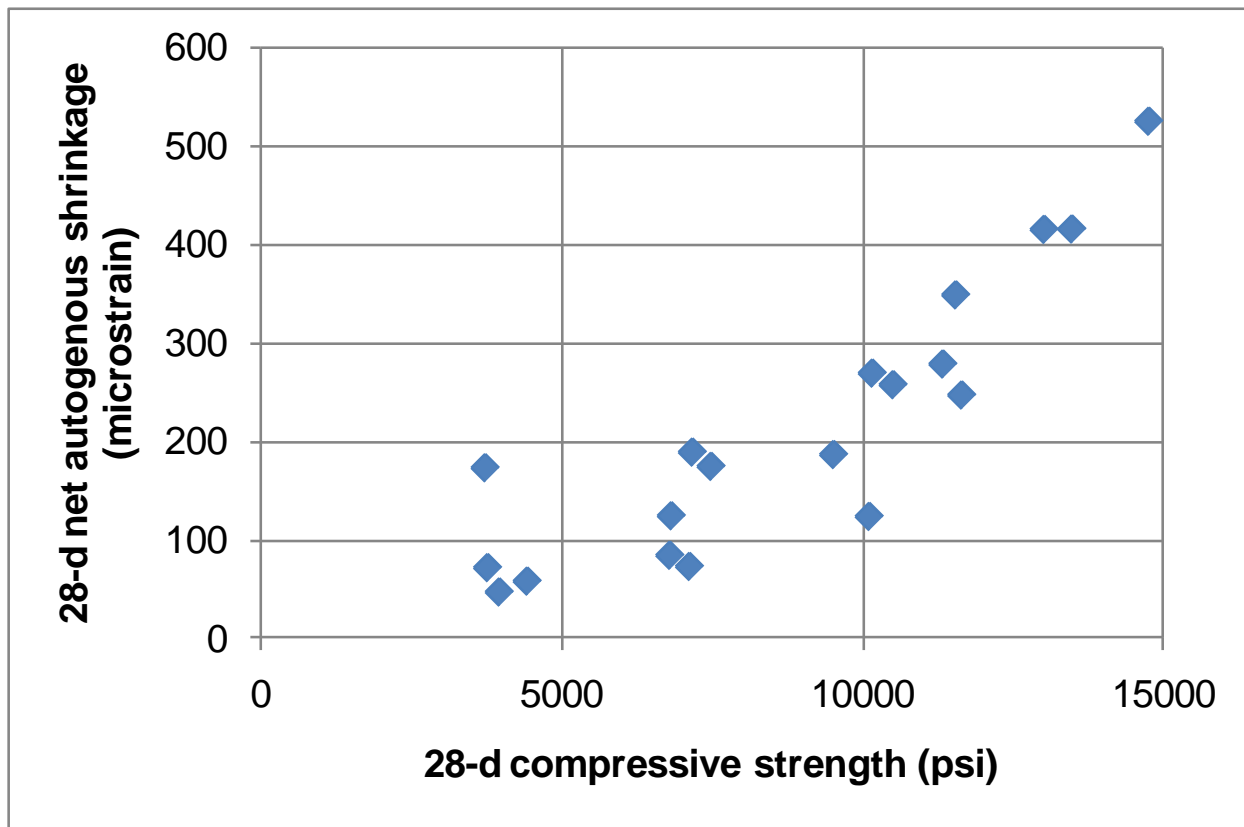

Figure 33. 28-d net autogenous shrinkage vs. 28-d compressive strength. 


\section{Conclusions}

The present study has indicated that cement fineness, fly ash fineness, and fly ash volume fraction all have significant influences on strength development and other early-age properties of blended cement mortars. Strengths at each of the six ages were well fit as linear functions of the three independent variables of cement surface area, fly ash surface area, and fly ash volume fraction, with correlation coefficients, $\mathrm{R}$, always greater than 0.97 . For the range of variables investigated in this study, cement surface area has a significant influence on strength development for ages out to $28 \mathrm{~d}$ and again at $182 \mathrm{~d}$, while fly ash surface area becomes significant from 28 days onward. Fly ash volume fraction has a very large influence on compressive strength at all tested ages, but its relative influence decreases with age, exemplifying the enhanced later age reactivity of fly ash in these blended cement mortars. A model based on the absolute surface areas of cement and fly ash in each mortar, along with the fly ash volume percentage, yielded correlation coefficients that were generally superior to those obtained by directly using the three independent variables, particularly at early ages. Furthermore, linear relations between cumulative heat release and compressive strengths for ages of $1 \mathrm{~d}, 3 \mathrm{~d}$, and $7 \mathrm{~d}$ and between autogenous deformation and compressive strength for an age of $28 \mathrm{~d}$ have been demonstrated.

With respect to the project objective of formulating high volume fly ash mixtures with $1 \mathrm{~d}$ and $28 \mathrm{~d}$ strengths equivalent to those of a control mortar with no fly ash prepared with the same volumetric proportions of sand, water, and binder (cement + fly ash), the results indicate that this goal is easily met for a fly ash volume fraction of $20 \%$ and can be met for a fly ash volume fraction of $35 \%$ with a judicious selection of the fly ash. In this study, a Class C fly ash was utilized to achieve this performance at the $35 \%$ level. Based on the compressive strength testing, it was demonstrated that the finer cements produced for this study are superior to the current practice of employing Type III cement in HVFA mixtures. In conclusion, the approach of combining a finer cement with a coarser fly ash to produce a superior blended product has merit, as demonstrated by the quantitative results obtained in this study. 


\section{Acknowledgements}

Funding for this study was provided by Roman Cement LLC, under CRADA CN-095142, “Optimization of Particle Sizes in High Volume Fly Ash Blended Cements.” The authors would like to thank Mr. John Winpigler and Mr. Max Peltz of the Engineering Laboratory at NIST for their assistance in carrying out the experiments described in this report. 


\section{References}

1) Bentz, D.P., Garboczi, E.J., Haecker, C.J., and Jensen, O.M., "Effects of Cement Particle Size Distribution on Performance Properties of Portland Cement-Based Materials," Cement and Concrete Research, 29 (10), 1663-1671, 1999.

2) Bentz, D.P., Jensen, O.M., Hansen, K.K., Olesen, J.F., Stang, H., and Haecker, C.J., "Influence of Cement Particle Size Distribution on Early Age Autogenous Strains and Stresses in Cement-Based Materials,” Journal of the American Ceramic Society, 84 (1), 129-135, 2001.

3) Bentz, D.P., Sant, G., and Weiss, W.J., "Early-Age Properties of Cement-Based Materials: I. Influence of Cement Fineness," ASCE Journal of Materials in Civil Engineering, 20 (7), 502508, 2008.

4) Bentz, D.P., "Blending Different Fineness Cements to Engineer the Properties of CementBased Materials,” Magazine of Concrete Research, 62 (5), 327-338, 2010.

5) Bentz, D.P., Bognacki, C.J., Riding, K.A., and Villareal, V.H., "Hotter Cements, Cooler Concretes,” Concrete International, 33 (1), 41-48, 2011.

6) Guynn, J.M., and Hansen, A.S., "High Early Strength Pozzolan Cement Blends,” U.S. Patent Application 12/576,117, Filing Date 10/08/2009.

7) Bentz, D.P., Ferraris, C.F., De la Varga, I., Peltz, M.A., and Winpigler, J., "Mixture Proportioning Options for Improving High Volume Fly Ash Concretes,” International Journal of Pavement Research and Technology, 3 (5), 234-240, 2010.

8) ASTM International, ASTM Standards on DISC, Vol. 04.01, West Conshohocken, PA, 2009.

9) ASTM International, ASTM Standards on DISC, Vol. 04.02, West Conshohocken, PA, 2009.

10) Ryan, T.P., Modern Experimental Design, Wiley \& Sons, Hoboken, 2007.

11) Bentz, D.P., and Turpin, R., "Potential Applications of Phase Change Materials in Concrete Technology,” Cement and Concrete Composites, 29 (7), 527-532, 2007.

12) Bentz, D.P., and Ferraris, C.F., "Rheology and Setting of High Volume Fly Ash Mixtures,” Cement and Concrete Composites, 32 (4), 265-270, 2010.

13) Bentz, D.P., Peltz, M.A., and Winpigler, J., "Early-Age Properties of Cement-Based Materials: II. Influence of Water-to-Cement Ratio," ASCE Journal of Materials in Civil Engineering, 21 (9), 512-517, 2009.

14) Bentz, D.P., and Jensen, O.M., "Mitigation Strategies for Autogenous Shrinkage Cracking,” Cement and Concrete Composites, 26 (6), 677-685, 2004.

15) Cusson, D., "Effect of Blended Cements on Efficiency of Internal Curing of HPC," in ACISP 256, Internal Curing of High-Performance Concretes: Laboratory and Field Experiences, American Concrete Institute, Farmington Hills, MI, 105-120, 2008.

16) Ferraris, C.F., “Concrete Rheology: Knowledge and Challenges,” $2^{\text {nd }}$ International RILEM Symposium on Advances in Concrete through Science and Engineering, Quebec Canada, 2006. 
17) Hackley, V.A, and Ferraris, C.F., “The Use of Nomenclature in Dispersion Science and Technology,” NIST Recommended Practice Guide, SP 960-3, 2001.

18) Schramm, G., “A Practical Approach to Rheology and Rheometry,” Haake, 1994.

19) Ferraris, C.F., Geiker, M., Martys, N.S., and Muzzatti, N., "Parallel-plate Rheometer Calibration Using Oil and Lattice Boltzmann Simulation," Journal of Advanced Concrete Technology, 5 (3), 363-371, 2007. 


\section{Appendix A - Procedures for Determining HRWRA Dosages}

Rheological measurements usually are represented as a plot of shear stress, $\sigma$, vs. shear rate, $\dot{\gamma}$ [16]. The apparent viscosity [17] is defined as the ratio of the shear stress over the shear rate at a given shear rate. For a Newtonian fluid (no yield stress), it is also equal to the slope of the fitted line of the shear stress-shear rate plot, going through zero, as the relationship is linear. However, most granular materials are non-Newtonian. Their main characteristic is that they exhibit a yield stress, $\sigma_{B}$, which is regarded as the stress needed to initiate deformation or flow of the material. There are several methods to measure the yield stress. The most common method is the extrapolation from the Bingham test method as described in equation 2. The plastic viscosity, $\eta_{p l}$, and the yield stress, are estimated from the regression. This procedure assumes that the plastic viscosity is defined as the slope of the shear stress - shear rate curve and that the yield stress is the intercept of the curve at a zero shear rate. This point is generally not measured so this constitutes an extrapolation (Figure 34). The Bingham rheological parameters (yield stress and plastic viscosity) characterize the flow curve within a limited range of shear rates when it is not linear over a wider range of shear rates.

$$
\sigma=\sigma_{B}+\eta_{p l} \dot{\gamma}
$$

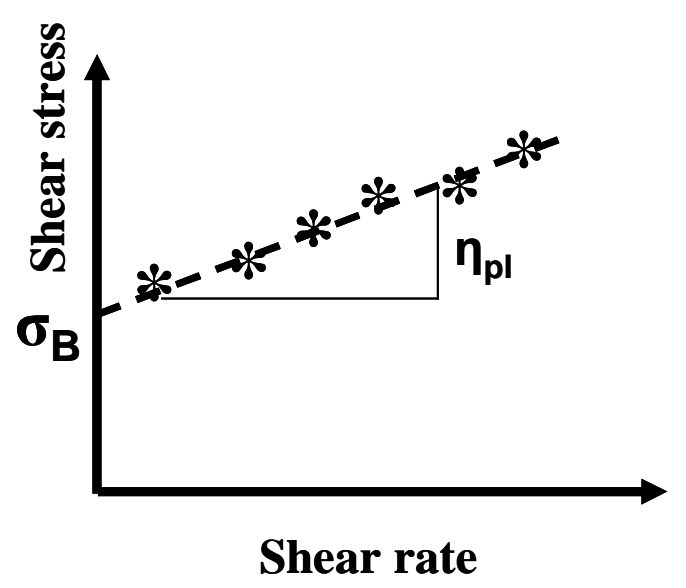

Figure 34: Bingham model and calculation of the plastic viscosity and yield stress.

The configuration of the rotational rheometer [18] used was a parallel plate with a diameter of $35 \mathrm{~mm}$, a serrated surface and with the gap varying from $0.4 \mathrm{~mm}$ upwards.

Cement paste rheological parameters are strongly affected by the amount of HRWRA added to the mixture. Usually, the yield stress and plastic viscosity decrease with an increase in the amount of HRWRA, until a maximum dosage is reached where the addition of HRWRA admixture does not change the rheological properties, a so-called saturation point. The rheological properties also change with time as the cement paste reacts and approaches initial set. The goal of these measurements was to estimate the optimum dosage of HRWRA for a given 
mixture as shown in Table 1. To determine this dosage while minimizing the amount of materials and time required, the following process was developed:

1) Prepare the mixture using a high-shear blender with temperature control. The temperature of the water bath is set at $15^{\circ} \mathrm{C}$, to obtain a paste at $21^{\circ} \mathrm{C}$. As soon as the mixing is completed, the temperature control is turned off and the material is kept covered.

2) Measure the rheological properties in the parallel plate rheometer using the following sequence [19] after placing the material between the plates: 1) $30 \mathrm{~s}$ of no shear to equilibrate with the temperature of $23{ }^{\circ} \mathrm{C}$; 2) $160 \mathrm{~s}$ of shear at $70 \mathrm{~s}^{-1}$ to homogenize the material; 3) increase the shear rate in steps from $1 \mathrm{~s}^{-1}$ to $50 \mathrm{~s}^{-1}$ and then decrease it to $1 \mathrm{~s}^{-1}$. The induced shear stresses are measured, corresponding to 10 shear rates when increasing the rotational velocity, and 10 additional levels when decreasing the rotational velocity. Each measured point is recorded after the shear stress reached equilibrium or after $20 \mathrm{~s}$, whichever occurs first. The descending data are regressed to a line using ordinary least squares (Figure 34), and the plastic viscosity and yield stress are estimated based on the Bingham equation (Eq. (2)).

3) If the plastic viscosity is high enough (above $0.30 \mathrm{~Pa} \cdot \mathrm{s}$ ) or the yield stress is above $50 \mathrm{~Pa}$, a dosage of HRWRA is added to the mixture and it is remixed for $30 \mathrm{~s}$ at $1050 \mathrm{rad} / \mathrm{s}$ [10,000 rpm]. The dosage is selected depending on the magnitude of the yield stress or plastic viscosity, in other words how far from the desired values the original measurements are.

4) After the addition of the HRWRA and remixing, points 2 and 3 are repeated until the desired rheological properties are obtained. If set occurs during this process, a new mixture is prepared and dosages are adjusted accordingly. Initial setting is easily detected by a significant increase of the rheological parameters and the development of a non-linear shear stress- shear rate curve.

The results obtained are shown in Table 7. For two of the mixtures, the dosage could only be estimated due to the fact that at all the examined dosages of HRWRA, the shear stress-shear rate curve was not linear and therefore, the yield stress and plastic viscosity could not be correctly estimated. These mixtures are marked Not linear in Table 7. 
Table 7: Results of rheological tests

\begin{tabular}{|c|c|c|c|c|c|}
\hline Mixture & $\begin{array}{c}\text { HRWRA } \\
\text { [g/300g of } \\
\text { cement] }\end{array}$ & $\begin{array}{c}\text { Yield } \\
\text { stress } \\
{[\mathrm{Pa}]}\end{array}$ & $\begin{array}{c}\text { Plastic } \\
\text { Viscosity } \\
\text { [Pa.s] }\end{array}$ & $\begin{array}{l}\text { Coefficient of } \\
\text { determination } \\
\left(\mathbf{R}^{2}\right)\end{array}$ & Comments \\
\hline 1 & 0 & 2.8 & 0.21 & 0.99 & \\
\hline 2 & 0 & 1.0 & 0.05 & 0.94 & \\
\hline 3 & 0 & 22.9 & 0.27 & 0.95 & \\
\hline 4 & 0 & 6.8 & 0.14 & 0.97 & \\
\hline \multirow[t]{2}{*}{5} & 0 & 335.7 & 2.27 & 0.89 & \\
\hline & 1.10 & 9.6 & 0.44 & 0.99 & \\
\hline \multirow[t]{2}{*}{6} & 0 & 107.5 & 0.62 & 0.95 & \\
\hline & 0.85 & 29.7 & 0.13 & 0.99 & \\
\hline 7 & 0 & 30.1 & 0.15 & 0.96 & \\
\hline \multirow[t]{2}{*}{8} & 0 & 287.9 & 1.41 & 0.99 & \\
\hline & 1.45 & 59.2 & 0.08 & 0.72 & \\
\hline 9 & 3.05 & 15.9 & 0.20 & 0.86 & Not linear \\
\hline \multirow[t]{2}{*}{10} & 0 & 131.9 & 0.65 & 0.98 & \\
\hline & 2 & 48 & 0.09 & 0.83 & Not linear \\
\hline 11 & 0 & 5.6 & 0.10 & 1.00 & \\
\hline \multirow[t]{2}{*}{12} & 0 & 66.5 & 0.32 & 0.96 & \\
\hline & 0.15 & 48.6 & 0.22 & 1.00 & \\
\hline \multirow[t]{2}{*}{13} & 0 & 37.5 & 0.31 & 0.99 & \\
\hline & 0.15 & 12.9 & 0.27 & 0.99 & \\
\hline \multirow[t]{2}{*}{14} & 0 & 402.9 & 1.53 & 0.85 & \\
\hline & 2.40 & 4.58 & 0.12 & 0.97 & \\
\hline 15 & 0 & 2.88 & 0.09 & 0.97 & \\
\hline \multirow[t]{2}{*}{16} & 0 & 65.61 & 0.58 & 1.00 & \\
\hline & 0.15 & 28.07 & 0.24 & 0.98 & \\
\hline \multirow[t]{2}{*}{17} & 0 & 534.23 & 2.60 & 0.94 & \\
\hline & 3.05 & 23.27 & 0.12 & 0.74 & \\
\hline 18 & 0 & 22.18 & 0.09 & 0.99 & \\
\hline
\end{tabular}




\section{Appendix B - Measured Compressive Strength Values for all Mixtures}

Table 8. Measured mortar cube compressive strengths (means and standard deviations) for the 20 mortar mixtures at each of six different ages.

\begin{tabular}{|c|c|c|c|c|c|c|c|}
\hline Mixture & $\begin{array}{l}\text { Run } \\
\text { Order } \\
\text { ID }\end{array}$ & $\begin{array}{l}\text { 1-d mean } \\
\text { strength } \\
\text { (psi) } \\
\text { (Std. dev.) }\end{array}$ & $\begin{array}{l}\text { 3-d mean } \\
\text { strength } \\
\text { (psi) } \\
\text { (Std. dev.) }\end{array}$ & $\begin{array}{l}\text { 7-d mean } \\
\text { strength } \\
\text { (psi) } \\
\text { (Std. dev.) }\end{array}$ & $\begin{array}{l}\text { 28-d mean } \\
\text { strength } \\
\text { (psi) } \\
\text { (Std. dev.) }\end{array}$ & $\begin{array}{l}\text { 91-d mean } \\
\text { strength } \\
\text { (psi) } \\
\text { (Std. dev.) }\end{array}$ & $\begin{array}{l}\text { 182-d mean } \\
\text { strength } \\
\text { (psi) } \\
\text { (Std. dev.) }\end{array}$ \\
\hline Control $^{\mathrm{A}}$ & 1 & $5320(72)$ & 7900 (340) & $9220(330)$ & $11640(430)$ & $12280(610)$ & $12470(600)$ \\
\hline Control repeat & $1 \mathrm{~A}$ & 5260 (180) & 7990 (260) & 9090 (580) & $11510(430)$ & $12750(510)$ & $13430(490)$ \\
\hline $50 \%$ fly ash & 2 & $1980(51)$ & 3090 (73) & $4250(240)$ & $7120(160)$ & $10240(240)$ & $11520(510)$ \\
\hline 35 \% FA 3-Cem 7 & 3 & 3980 (150) & $5780(130)$ & $7380(220)$ & $10100(290)$ & $11480(230)$ & $13170(570)$ \\
\hline 35 \% FA 2-Cem 8 & 5 & $5500(210)$ & $6960(140)$ & $8600(250)$ & $9510(460)$ & $11180(310)$ & $11860(710)$ \\
\hline 35 \% FA 5-Cem 9 & 8 & 5660 (210) & $7380(42)$ & 8460 (220) & $10150(170)$ & $12030(280)$ & $12890(580)$ \\
\hline $35 \%$ FA 4-Cem 10 & 10 & 6460 (190) & 7750 (370) & $9400(280)$ & $10500(200)$ & $11690(580)$ & $12080(300)$ \\
\hline $35 \%$ C ash -Cem 9 & 19 & 5620 (190) & 7460 (140) & $8910(280)$ & $11540(560)$ & $12450(90)$ & 13180 (1050) \\
\hline 35 \% FA 5-Type III & 20 & $4610(90)$ & $6620(410)$ & $7200(250)$ & $9620(500)$ & $11260(340)$ & Not measured \\
\hline 50 \% FA 2-Cem 7 & 4 & $2300(130)$ & $3600(140)$ & $4780(170)$ & $6790(43)$ & $8520(38)$ & $9620(220)$ \\
\hline 50 \% FA 5-Cem 8 & 16 & $3240(100)$ & $4660(74)$ & $5810(140)$ & $7480(240)$ & $9410(460)$ & $10390(600)$ \\
\hline 50 \% FA 4-Cem 9 & 6 & $3300(31)$ & $4620(85)$ & $5550(170)$ & $6820(220)$ & 8160 (190) & $9450(200)$ \\
\hline 50 \% FA 3-Cem 10 & 12 & $3650(52)$ & 4880 (200) & $5910(100)$ & 7170 (260) & $8360(220)$ & 9190 (430) \\
\hline $65 \%$ FA 5-Cem 7 & 15 & $1210(39)$ & $2110(44)$ & $2660(57)$ & $4430(200)$ & $6910(44)$ & $8270(370)$ \\
\hline 65 \% FA 4-Cem 8 & 11 & $1480(35)$ & $2130(73)$ & $2720(84)$ & $3960(70)$ & $5530(140)$ & $7160(370)$ \\
\hline 65 \% FA 3-Cem 9 & 18 & $1480(45)$ & $2150(48)$ & $2770(62)$ & 3730 (69) & $5180(130)$ & $6710(250)$ \\
\hline $65 \%$ FA 2-Cem 10 & 7 & $1700(73)$ & $2310(42)$ & $2780(44)$ & $3770(21)$ & 4790 (230) & $6060(80)$ \\
\hline 20 \% FA 4-Cem 7 & 13 & $5320(91)$ & $7360(220)$ & $9220(460)$ & $11330(360)$ & $13020(270)$ & $13310(780)$ \\
\hline 20 \% FA 3-Cem 8 & 14 & $7770(84)$ & $9940(460)$ & $11620(300)$ & $13010(830)$ & $13620(640)$ & $14440(820)$ \\
\hline $20 \%$ FA 2-Cem 9 & 17 & 7910 (330) & $9680(370)$ & $11370(430)$ & $13470(590)$ & $13680(600)$ & $13960(760)$ \\
\hline $20 \%$ FA 5-Cem 10 & 9 & $9590(250)$ & $11070(210)$ & $12460(270)$ & $14740(570)$ & $15510(890)$ & $15250(370)$ \\
\hline
\end{tabular}

${ }^{\mathrm{A}}$ Order of mixtures in the table is the same as that used in the compressive strength plots in Figures 7, 8, and 9. 


\section{Appendix C - Measured 28-d Net Autogenous Shrinkages for all Mixtures}

Table 9. Measured 28-d net autogenous shrinkages for the 20 mortar mixtures.

\begin{tabular}{|c|c|c|}
\hline Mixture & $\begin{array}{c}\text { Run } \\
\text { Order } \\
\text { ID }\end{array}$ & $\begin{array}{c}\text { 28-d net autogenous } \\
\text { shrinkage } \\
\text { (microstrain) }\end{array}$ \\
\hline Control & 1 & 247 \\
\hline Control repeat & $1 \mathrm{~A}$ & 175 \\
\hline 50 \% fly ash & 2 & 74 \\
\hline $35 \%$ FA 3-Cem 7 & 3 & 125 \\
\hline $35 \%$ FA 2-Cem 8 & 5 & 187 \\
\hline $35 \%$ FA 5-Cem 9 & 8 & 269 \\
\hline $35 \%$ FA 4-Cem 10 & 10 & 258 \\
\hline $35 \%$ C ash -Cem 9 & 19 & 348 \\
\hline $35 \%$ FA 5-Type III & 20 & Not measured \\
\hline $50 \%$ FA 2-Cem 7 & 4 & 85 \\
\hline $50 \%$ FA 5-Cem 8 & 16 & 175 \\
\hline $50 \%$ FA 4-Cem 9 & 6 & 125 \\
\hline $50 \%$ FA 3-Cem 10 & 12 & 190 \\
\hline $65 \%$ FA 5-Cem 7 & 15 & 59 \\
\hline $65 \%$ FA 4-Cem 8 & 11 & 48 \\
\hline $65 \%$ FA 3-Cem 9 & 18 & 174 \\
\hline $65 \%$ FA 2-Cem 10 & 7 & 73 \\
\hline $20 \%$ FA 4-Cem 7 & 13 & 279 \\
\hline $20 \%$ FA 3-Cem 8 & 14 & 415 \\
\hline $20 \%$ FA 2-Cem 9 & 17 & 415 \\
\hline $20 \%$ FA 5-Cem 10 & 9 & 524 \\
\hline
\end{tabular}

